\title{
Simulation of Severe Local Storm by Mesoscale Model MM5 and Validation Using Data from Different Platforms
}

\author{
Prosenjit Chatterjee, ${ }^{1}$ Utpal Kumar De, ${ }^{2}$ and Devendra Pradhan ${ }^{3}$ \\ ${ }^{1}$ Birbhum Institute of Engineering and Technology, Suri 731101, India \\ ${ }^{2}$ School of Environmental Studies, Jadavpur University, Kolkata 700032, India \\ ${ }^{3}$ Regional Meteorological Centre, Government of India, 4 Duel Avenue, Alipore, Kolkata 700027, India
}

Correspondence should be addressed to Prosenjit Chatterjee; chprosenjit_ju@yahoo.com

Received 30 September 2014; Revised 14 January 2015; Accepted 20 January 2015

Academic Editor: Luiz Machado

Copyright (C) 2015 Prosenjit Chatterjee et al. This is an open access article distributed under the Creative Commons Attribution License, which permits unrestricted use, distribution, and reproduction in any medium, provided the original work is properly cited.

\begin{abstract}
During premonsoon season (March to May) convective developments in various forms are common phenomena over the Gangetic West Bengal, India. In the present work, simulation of wind squall on three different dates has been attempted with the help of mesoscale model MM5. The combination of various physical schemes in MM5 is taken as that found in a previous work done to simulate severe local storms over the Gangetic West Bengal. In the present study the model successfully simulates wind squall showing pressure rise, wind shift, wind surge, temperature drop, and heavy rainfall, in all cases. Convective cloud development and rainfall simulation by the model has been validated by the corresponding product from Doppler Weather Radar located at Kolkata and TRMM satellite product 3B42 (V6), respectively. It is found that the model is capable of capturing heavy rainfall pattern with up to three-hour time gap existing between simulation and observation of peak rainfall occurrence. In all simulations there is spatial as well as temporal shift from observation.
\end{abstract}

\section{Introduction}

Over the Gangetic Plain of West Bengal (GWB), India, and its surroundings, several types of convective developments occur during premonsoon season (March to May). The most dominant formations are known as Nor'wester. This type of thunderstorm development occurs due to collision of two different kinds of air masses, that is, the dry land based airmass coming from northwest and the moist hot maritime airmass coming from south or southeast. GWB and neighbouring Bangladesh experience these Nor'westers, which are locally called Kal Baisakhi. They produce squall line, wind squall, heavy rain showers, hailstorm, and tornadoes which appear as natural hazard. They also pose serious hazards to aviation activities.

Conditions favourable for occurrence of severe convective phenomena are advection of warm moist air in the lower troposphere along with cold dry air aloft, thus generating latent instability. Synoptic situations, which cause conditions conductive to vertically upward motion of air, are also needed. These may be manifested as a line of discontinuity, a trough, a low pressure area, or a cyclonic circulation leading to convergence in the lower level. The upper troposphere normally has a trough in the westerlies or subtropical westerly jet or a combination of both (trough-jet) providing divergences. Any one or a combination of two or more of the above situations may cause severe local storm. Usually a trigger in the form of intense insolation is needed to initiate the process of convective phenomena [1].

In the present work, our main objective is to simulate wind squall with all its associated features over GWB and surrounding regions, with the help of a mesoscale model. In fact, such systems are quite frequent in this region and create quite havoc during their short span of life. The strong wind associated with such systems can destroy standing crops, uproot large trees, overturn electric poles, and damage weak structures. Loss of life occurs many a time and the mobility of people gets disrupted to a large extent. So, study of wind squall has great importance for the concerned locality. 
Incidentally, the mesoscale model MM5 developed by Penn State University, US, and National Center for Atmospheric Research, US, is a very widely used model and nearly 500 research publications are available in the literature involving MM5/MM4. The model is successful in simulating varied form of mesoscale and regional scale systems over different parts of the globe. It has been used over Bay of Bengal to simulate tropical cyclone by Patra et al. [2]; Rao and Prasad [3]; Srinivas et al. [4]; and Sandeep et al. [5], cyclone track by Mohanty and Mandal [6], depression by Kumar and Chandrasekar [7], and the convective clouds by Zuideme [8]. A work on mountain weather forecasts over the Indian region using MM5 model was carried out by Das et al. [9]. A simulation study of Orissa Super Cyclone [10] using MM5 model was made jointly by Mohanty et al. in 2004. During the field study of STORM program in India in the year 2006, Litta and Mohanty [11] published a paper on simulation study of a severe thunderstorm event. Litta et al. [12] studied numerical simulation of a tornado over Ludhiana in India using WRF-NMM model. A work on simulation of severe Land-Falling of Bay of Bengal Cyclones during 1995-1999 using MM5 model was done by Mandal and Mohanty [13] where they had used synthetic vortex technique to simulate the cyclones. A comparative study of thunderstorm simulation over eastern part of India using WRF-NMM and WRF-ARW was carried out by Litta et al. [14]. A study of numerical simulation of severe local storm over eastern part of India has been done using WRF-NMM model by Litta et al. [15]. In the same year they also carried a diagnostic study of severe thunderstorm with the same model which can be found in Litta et al. [16]. Madan et al. [17] have made some study on forecasting peak surface gust wind in association with thunderstorm activity during premonsoon season at Delhi. As these Nor'westers and associated wind squall make destruction during propagation over GWB region simulation, study of these systems over these regions is important for mitigation purpose. Successful prediction of intensity, time, and track of these systems can reduce loss of life, crop, and property. As MM5 model is an open source model capable for simulation of this small scale convective system it can be explored for this type of study. However, only a few works by Chatterjee et al. [18]; NCMRWF scientific publications (http://www.ncmrwf.gov.in/Rev-Publication_04Sep.pdf), and so forth have come to our notice involving use of the model for the simulation of convective system like Nor'wester and associated wind squall over a land mass close to the Bay of Bengal. More such study is needed for the social importance due to impact of Nor'wester. In addition we can explore the strength and weakness of MM5 for the study of different aspect of these local convective storms. Quantitative precipitation forecasting is one of the challenging issues particularly in case of heavy rainfall which is a common occurrence during these Nor'westers [19]. Numerical models allow for the prediction of individual convective storms on the model grid, but they often displace the storms in space, time, and intensity, which results in added uncertainty [20]. Previous studies indicate a need for better verification techniques, taking into account the discontinuous nature of precipitation fields, to enable us to diagnose better what is going wrong with the models and why. Pattern matching using satellite derived precipitation observation is one useful way. Area average rainfall verification is another scope of study. The performance of the present model about quantitative precipitation forecasting is verified in the present work. All these are the purpose of our present study. In the present study we have considered three local convective storms cases with wind squalls to find the performance of MM5 in local convective storm simulation over GWB. In this paper experimental configuration including model description has been described first and then methodology followed by description of Norwester cases. Lastly analysis of experimental result has been given with a conclusion at the end. In order to validate the model products, observations from Doppler Weather Radar (DWR) and Satellite are utilized. In the present work the model is being used to simulate developments with wind squall over GWB.

\section{Materials and Methods}

2.1. Model. The details of the model MM5 already exist in the literature written by Grell et al. [21]. However, in a nutshell the basic characteristics are being stated here. It is nonhydrostatic and regional in nature, with terrain following sigma coordinates in the vertical. There are 23 vertical levels. MM5 version 3.5 is being used here.

In MM5, the concerned physical processes are cumulus parameterization, cloud microphysics, planetary boundary layer, land surface, convection, and radiation. In the model more than one scheme are available in case of these six physical processes. While each of cumulus parameterization, cloud microphysics or explicit moisture scheme, and planetary boundary layer parameterization has eight schemes, radiation process has five schemes and land surface process has four schemes. In case of convection, there are two possibilities. The present authors have shown in a recent publication Chatterjee et al. [18] that the combination of schemes given in Table 1 without shallow convection option is suitable for the simulation of severe local storms over GWB region.

Nesting has been done from $90 \mathrm{~km}$ coarse resolution to $30 \mathrm{~km}$ and then to $10 \mathrm{~km}$ finer resolution. The mother domain of the present study covers an area with $2520 \mathrm{Km}$ in the north-south $\left(13.7^{\circ} \mathrm{N}\right.$ to $\left.36.3^{\circ} \mathrm{N}\right)$ and $3420 \mathrm{~km}$ in the east-west direction $\left(71.6^{\circ} \mathrm{E}\right.$ to $\left.102.4^{\circ} \mathrm{E}\right)$, and the domain of $10 \mathrm{~km}$ resolution has coverage of $820 \mathrm{~km}\left(20.5^{\circ} \mathrm{N}\right.$ to $\left.26.5^{\circ} \mathrm{N}\right) \times$ $790 \mathrm{~km}\left(83^{\circ} \mathrm{E}\right.$ to $\left.91^{\circ} \mathrm{E}\right)$ (Figure 1). Choices of parameterization schemes of different physical processes are based on the previous study by Chatterjee et al. [18] regarding wind squall simulation, which are written in Table 1.

2.2. Data Used. The final analysis data of Data Server Section (DSS) of the National Centers of Environmental Prediction (NCEP), US, available at 1 degree $\times 1$ degree grid network covering the entire globe, are used to provide initial and boundary values for the model run. The regional surface and RS/RW data from IMD and DSS observations (Table 2) within the domain were used by Cressman [26] or 


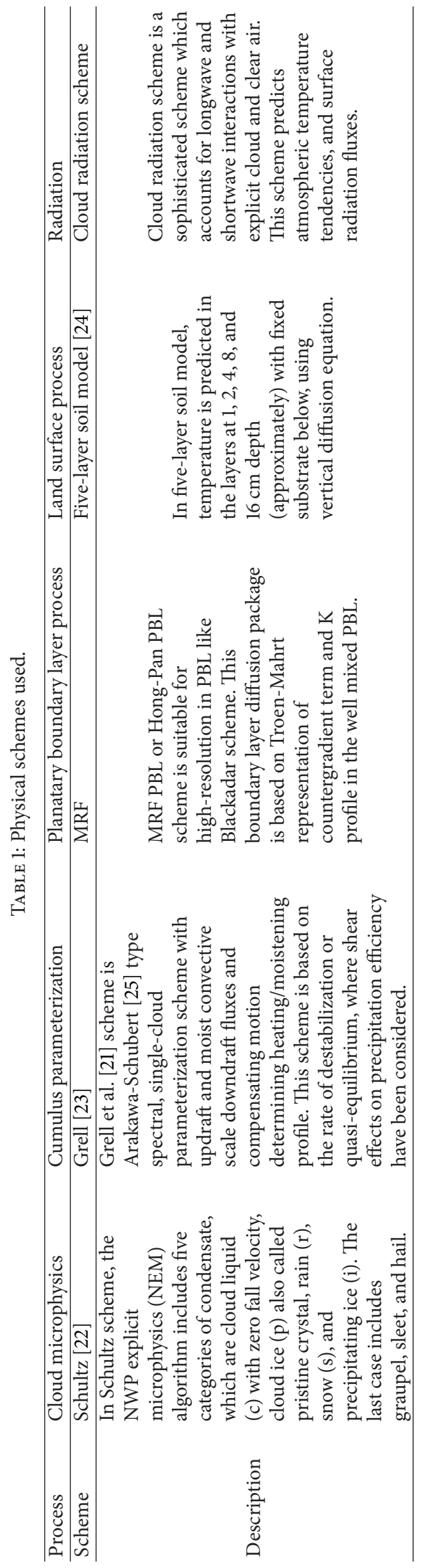


TABLE 2: Details of various data used.

\begin{tabular}{llcl}
\hline Platform & Data & Frequency & Application \\
\hline IMD (surface) & $\begin{array}{l}\text { Temperature, pressure, due-point temperature, relative } \\
\text { humidity, wind speed and direction. }\end{array}$ & 3 hours & $\begin{array}{l}\text { Model input as observation } \\
\text { to improve simulation }\end{array}$ \\
\hline IMD (RS/RW) & $\begin{array}{l}\text { Temperature, due-point temperature, relative humidity, } \\
\text { wind speed and direction at pressure levels. }\end{array}$ & $\begin{array}{l}\text { Model input as observation } \\
\text { to improve simulation }\end{array}$ \\
\hline DSS (surface) & $\begin{array}{l}\text { Temperature, pressure, due-point temperature, relative } \\
\text { humidity, wind speed and direction. }\end{array}$ & 6 hours & $\begin{array}{l}\text { Model input as observation } \\
\text { to improve simulation }\end{array}$ \\
\hline DSS (RS/RW) & $\begin{array}{l}\text { Temperature, due-point temperature, relative humidity, } \\
\text { wind speed and direction at pressure levels. }\end{array}$ & 12 hours & $\begin{array}{l}\text { Model input as observation } \\
\text { to improve simulation }\end{array}$ \\
\hline DSS (global model) & FNL & 6 hours & $\begin{array}{l}\text { Model input as initial and } \\
\text { boundary data }\end{array}$ \\
\hline IMD (Doppler radar) & Max(Z), VIL & 1 hour & Model verification \\
\hline TRMM & Rainfall & 3 hours & Model verification \\
\hline
\end{tabular}

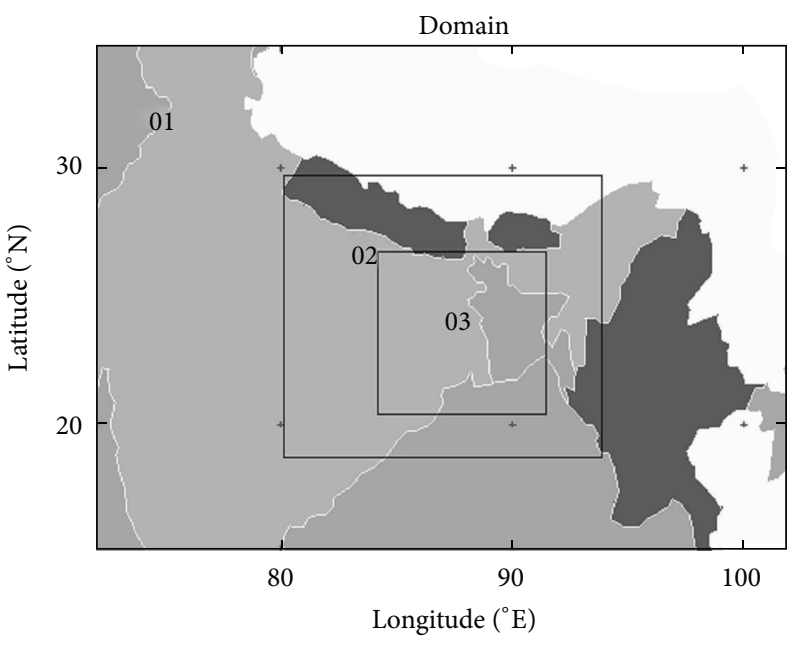

(a)

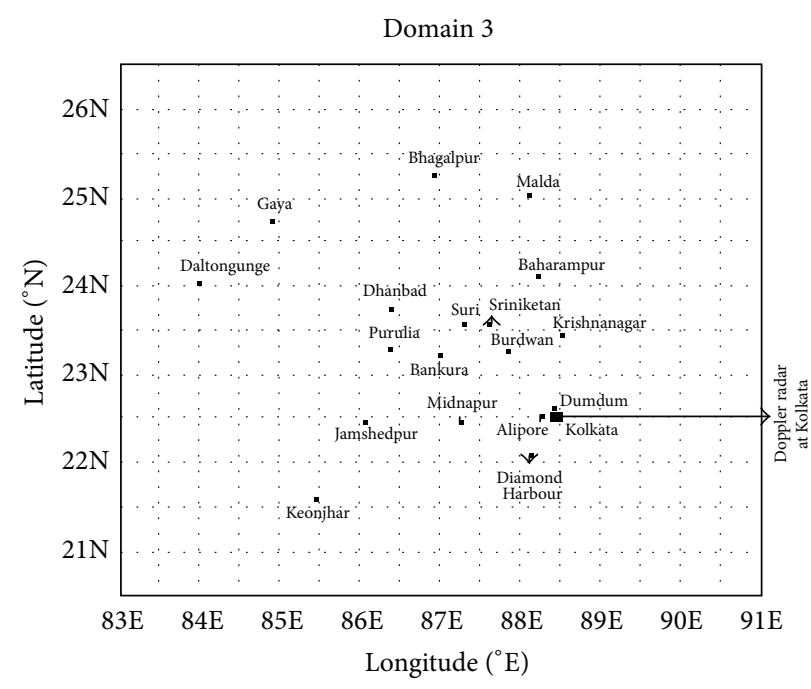

(b)

FIGURE 1: Domains 1, 2, and 3 of resolution of $90 \mathrm{~km}, 30 \mathrm{~km}$, and $10 \mathrm{~km}$, respectively, with plot of different stations on domain 3.

Multiquadric [27] objective analysis process to make model simulation closure to the observation.

2.3. Methods. As we are going to simulate Nor'wester and associated severe local storm, which is regional scale system, and as the Nor'westers are usually initiated over Chota Nagpur Plateau and move towards southeast, we choose our domains such that the model can capture these systems even in the presence of any external influence. In the present study, the centre of the domain after second nesting is $248 \mathrm{Km}$ away from Bankura $\left(23.25^{\circ} \mathrm{N}, 87.05^{\circ} \mathrm{E}\right)$ in the northern direction. The model has been run for 48 hours. However, it is being analyzed for $10 \mathrm{Km}$ resolution and for 27 hours only. Surface and RS/RW observation data of India Meteorological Department (IMD) are utilized for improvement of initial and boundary condition values by objective analysis technique. During the model run, the data input are made at an interval of 3 hours. The surface observations of many stations are available at an interval of 3 hours and RS/RW data are available at an interval of 12 hours only. NCEP final analysis data of every 6 hours' interval are created from the available 3 hours' interval data and these are given as input. For the interpolation of field values to the grid point values, either Cressman [26] or multiquadric method by Nuss and Titley [27] is used, depending upon the better result. Multiquadric method is unsuitable for less number of observations. So first the model has been run using both methods one by one and then the output has been analyzed to find out the suitability of the methods for different cases having different number of observation data. The radius of influence is taken as $15 \mathrm{Km}$ for Cressman method. The model integrates for four and half minutes only and then the output is taken as initial condition for the integration in the next step. The output is being analyzed at 9-minute interval.

As the synoptic scale features have significant influence on mesoscale developments, we compare the model initial values of temperature and pressure obtained from NCEP fnl data with those of observation on a synoptic scale.

A thunderstorm is in general associated with various motions; but, here model simulated horizontal wind speed 


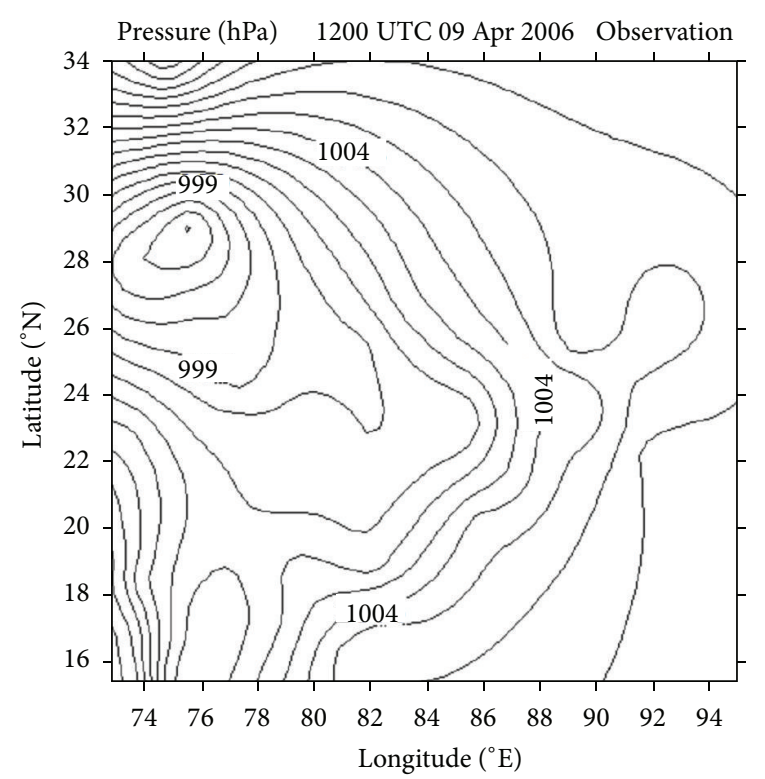

(a)

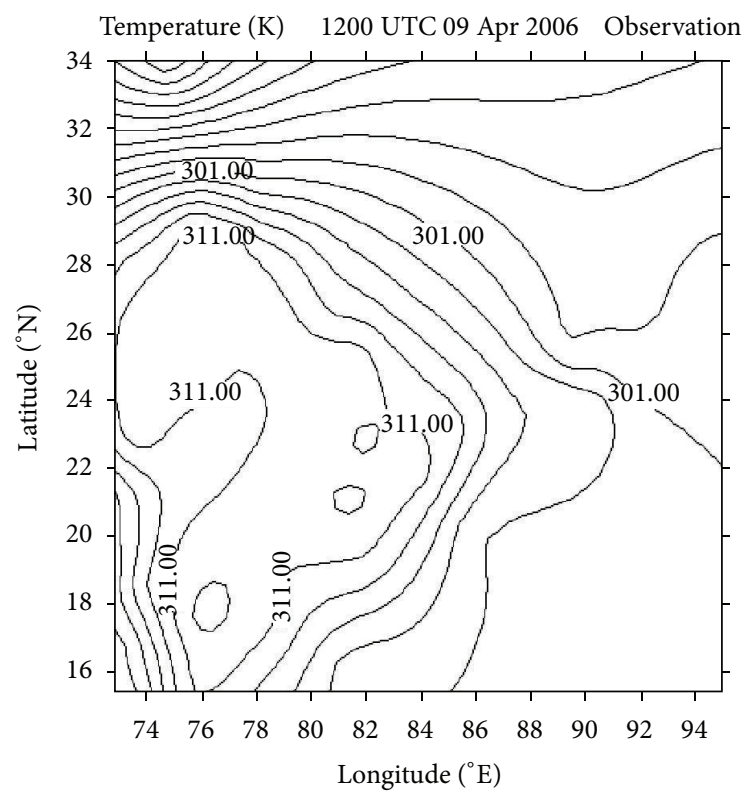

(c)

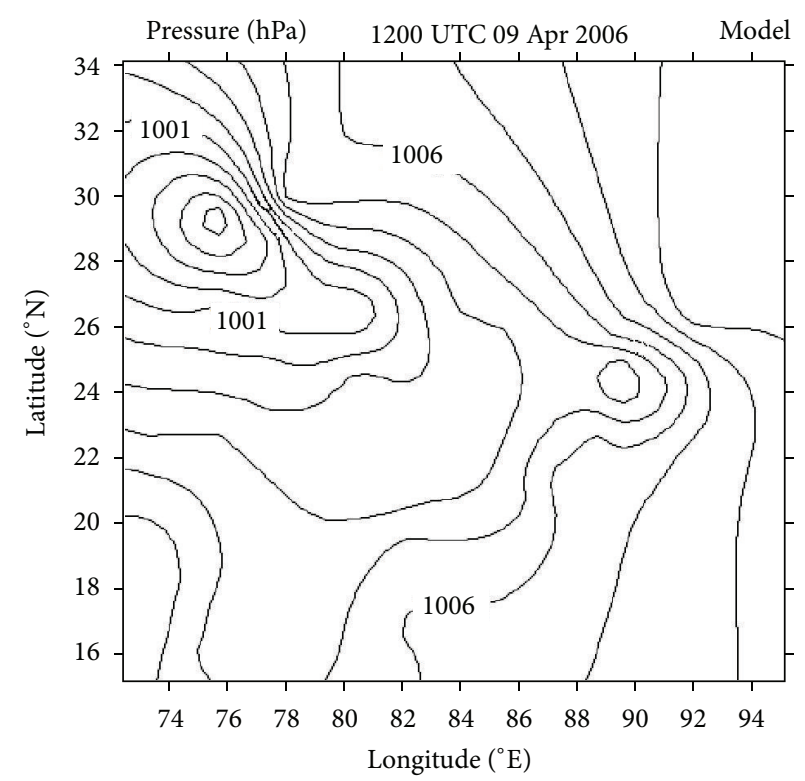

(b)

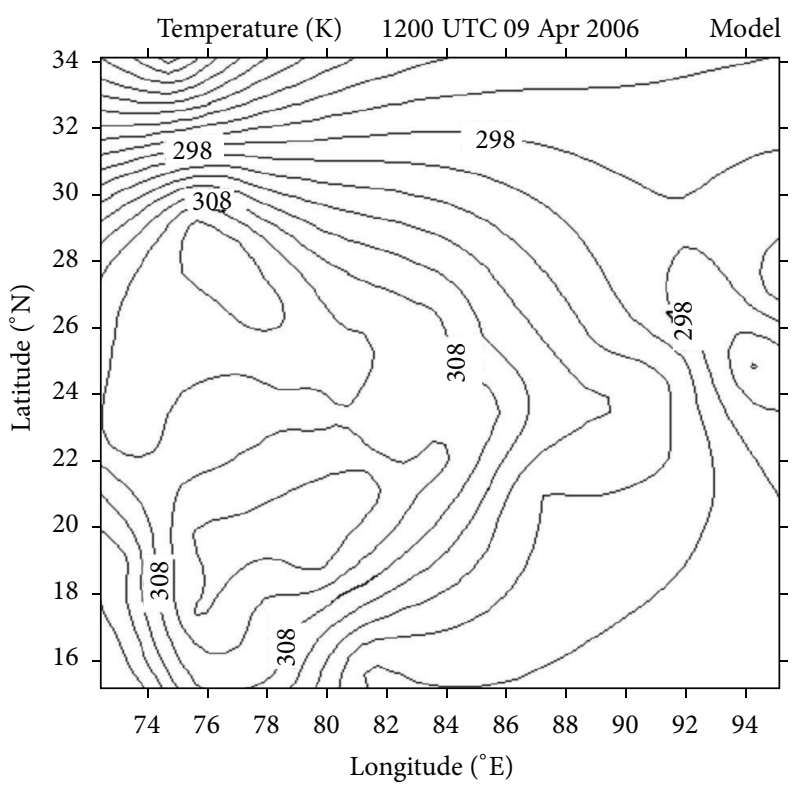

(d)

FIGURE 2: (a) Contour of observed mean sea level pressure at time $t=0$ of model integration for the system of April 10, 2006. (b) Contour mean sea level pressure created from fnl data of the global data at time $t=0$ of model integration for the system of April 10, 2006. (c) Contour of observed surface temperature at time $t=0$ of model integration for the system of April 10, 2006. (d) Contour of surface temperature created from fnl data of the global model at $t=0$ of model integration.

and direction, temperature fall and pressure rise are analyzed, and the first two products are compared with IMD observation.

Model simulated reflectivity and integrated rain water (IRW) are compared with the equivalent products of the Doppler radar situated at Kolkata $\left(22.55^{\circ} \mathrm{N}, 88.40^{\circ} \mathrm{E}\right)$, like reflectivity $\operatorname{Max}(Z)$ and vertically integrated liquid (VIL), respectively. Doppler radar has scan range of $500 \mathrm{Km}$ and display range of $250 \mathrm{Km}$ for $\operatorname{Max}(\mathrm{Z})$; but, for the VIL product, the scan range shrinks to $300 \mathrm{Km}$ and display range to $200 \mathrm{Km}$. For comparison between radar observation and model output, closest simulation time has a lag of maximum \pm 4 minutes as the model output is analyzed only at an interval of 9 minutes, whereas the radar output is available at an interval of 5 minutes only.

MM5 model output of total accumulated precipitation is compared with satellite TRMM 3B42 (V6) data. 


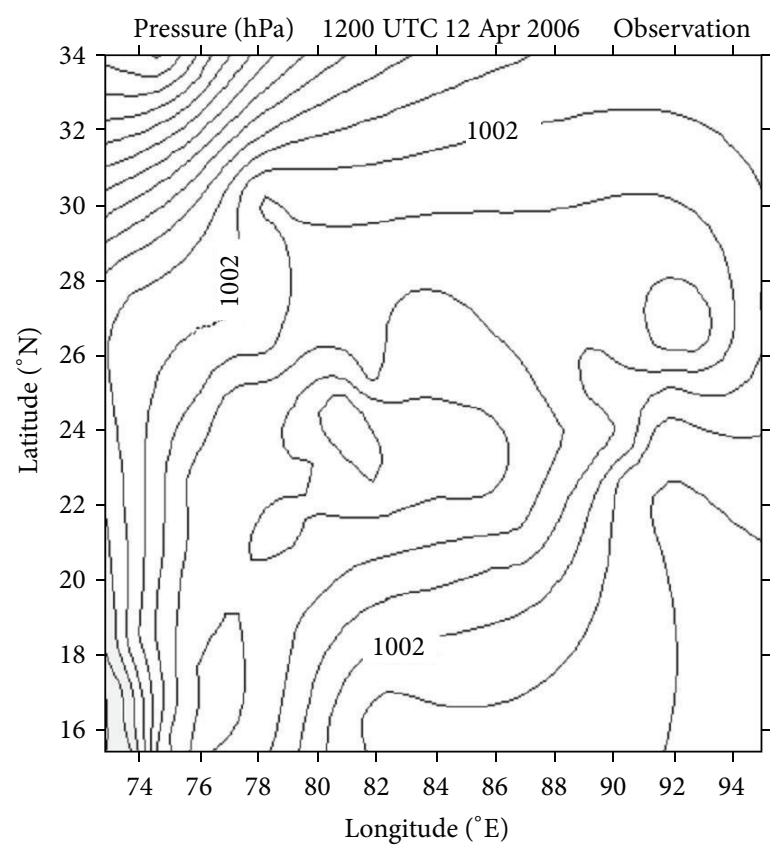

(a)

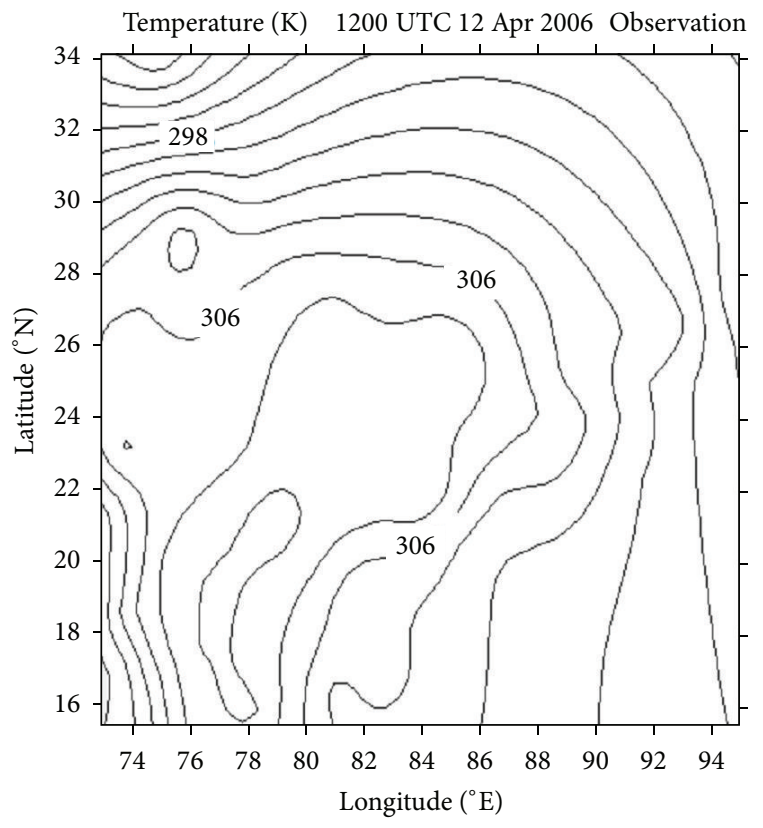

(c)

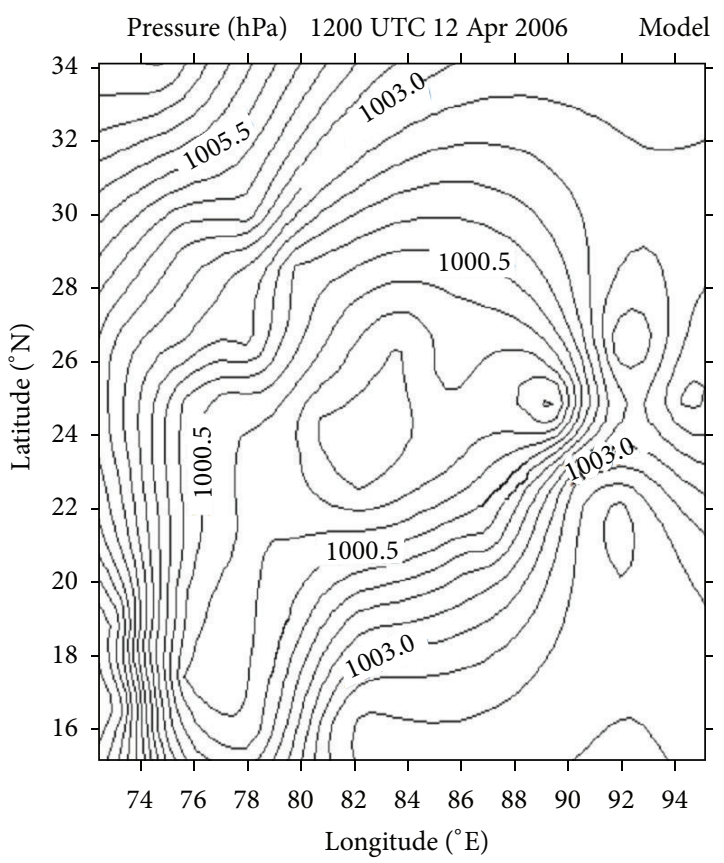

(b)

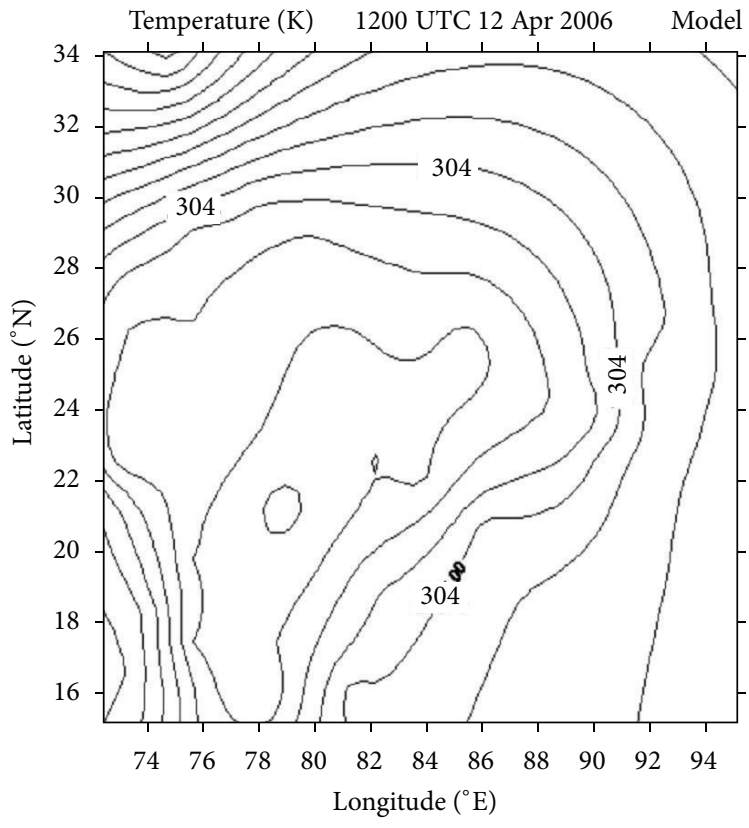

(d)

FIgURE 3: (a) Contour of observed mean sea level pressure at time $t=0$ of model integration for the system of April 13, 2006. (b) Contour mean sea level pressure created from fnl data of the global data at time $t=0$ of model integration for the system of April 13, 2006. (c) Contour of observed surface temperature at time $t=0$ of model integration for the system of April 13, 2006. (d) Contour of surface temperature created from fnl data of the global model at $t=0$ of model integration.

\section{Results and Discussion}

3.1. Nor'wester Cases. In the present study the following three storms are considered which are reported to be associated with wind squall and also hailstorm in two cases. Any thunderstorm produces gust front, which may turn into a high speed wind squall in some cases. Following a standard norm [28, 29], the wind speed must increase by at least 3 stages on the Beaufort scale (which may be taken as 16 Knots on the average or $8.82 \mathrm{~m} / \mathrm{s}$ ) and the speed must rise to force 6 (minimum $11.3 \mathrm{~m} / \mathrm{s}$ ) or more in the same scale, in order to be called a wind squall. The peak wind must last for a minute at least. The highest wind speed in these squalls may go even beyond $28 \mathrm{~m} / \mathrm{s}$. The following features are noted on 


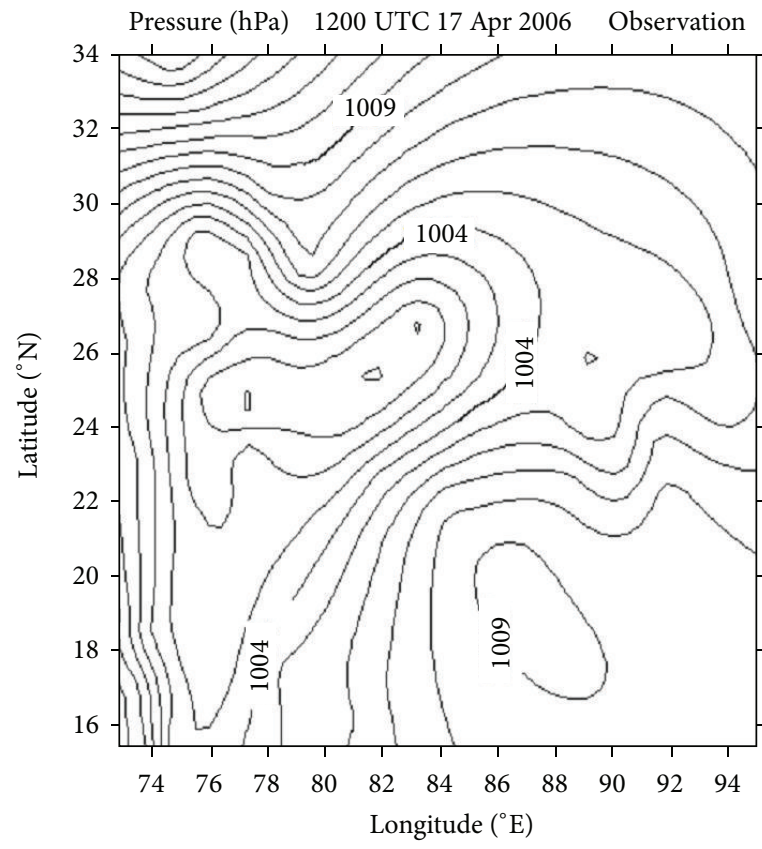

(a)

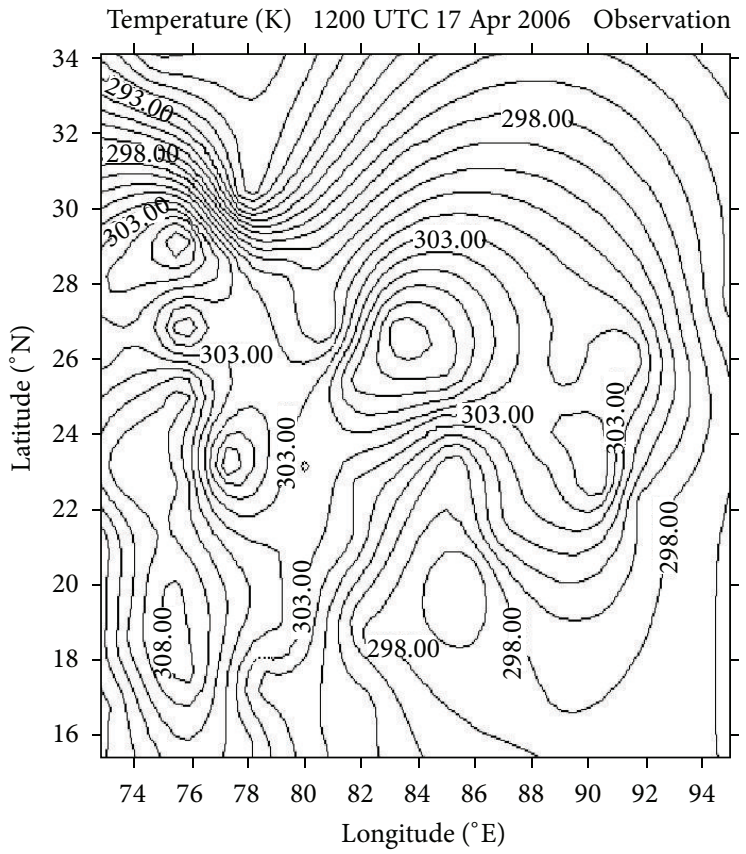

(c)

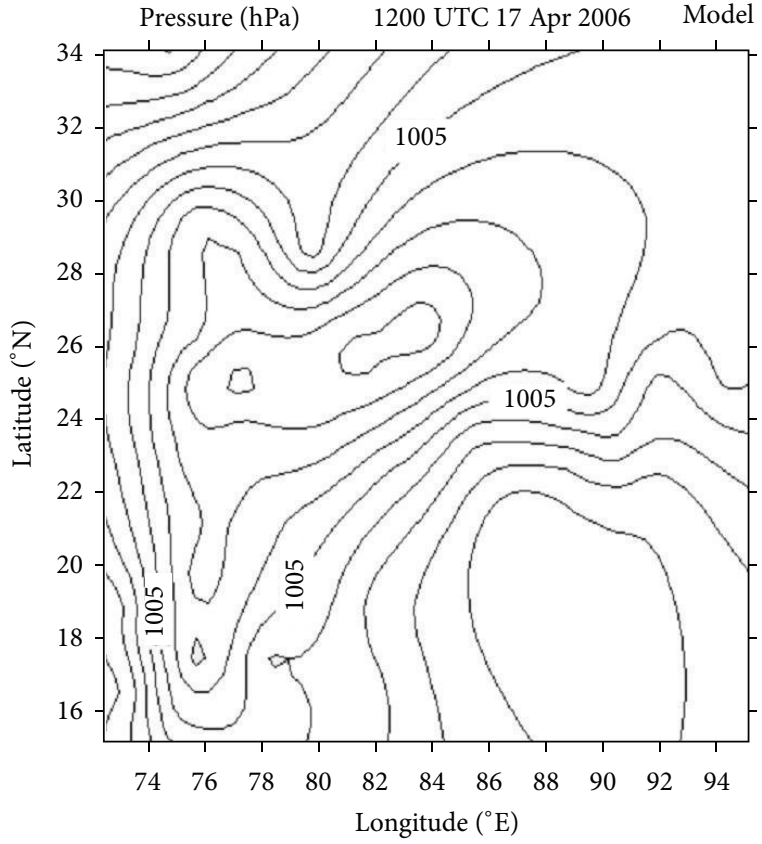

(b)

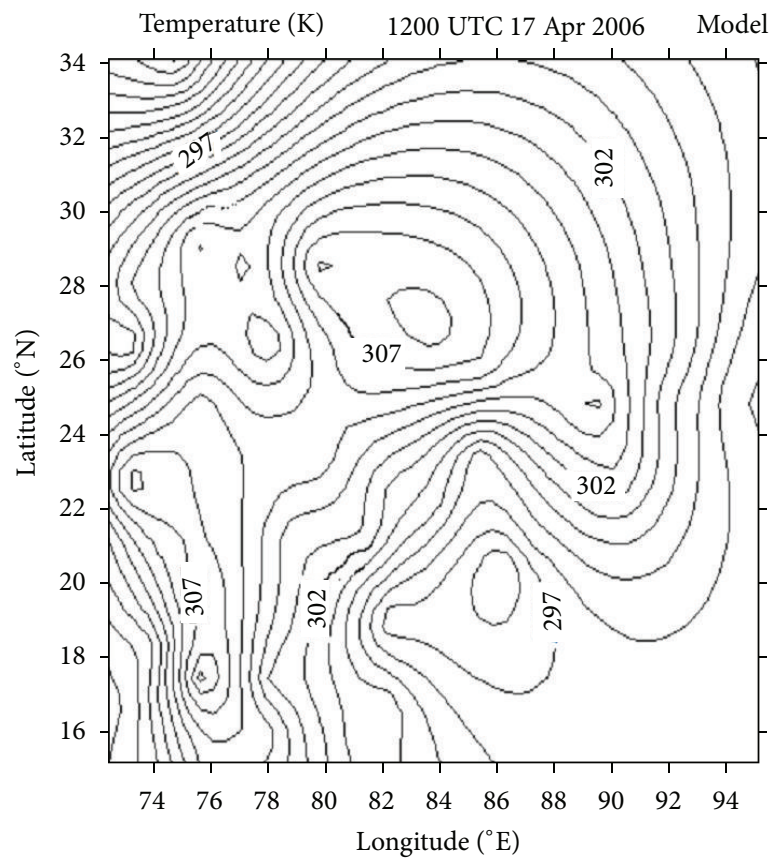

(d)

Figure 4: (a) Contour of observed mean sea level pressure at time $t=0$ of model integration for the system of April 18, 2006. (b) Contour mean sea level pressure created from fnl data of the global data at time $t=0$ of model integration for the system of April 18, 2006. (c) Contour of observed surface temperature at time $t=0$ of model integration for the system of April 18, 2006. (d) Contour of surface temperature created from fnl data of the global model at $t=0$ of model integration.

the sequence of meteorological events accompanied by wind squall as it passes over a surface recording station [30,31]:

(i) a rise in pressure (pressure rise),

(ii) a change in wind direction (wind shift),

(iii) a sudden increase in wind speed (wind surge), (iv) a drop in temperature (temperature drop or break),

(v) rainfall.

It should be mentioned that all wind squalls are not always associated with rain. 


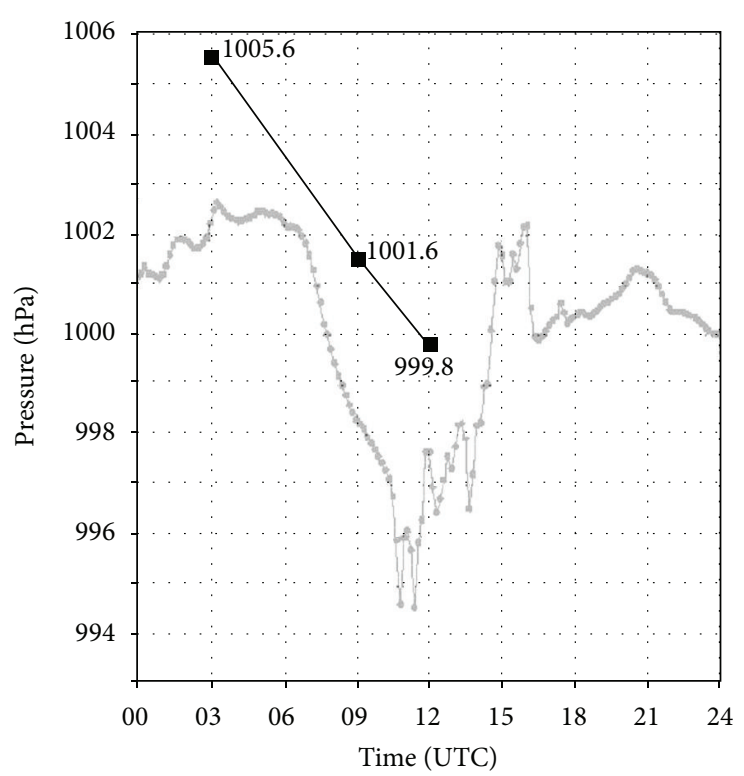

(a)

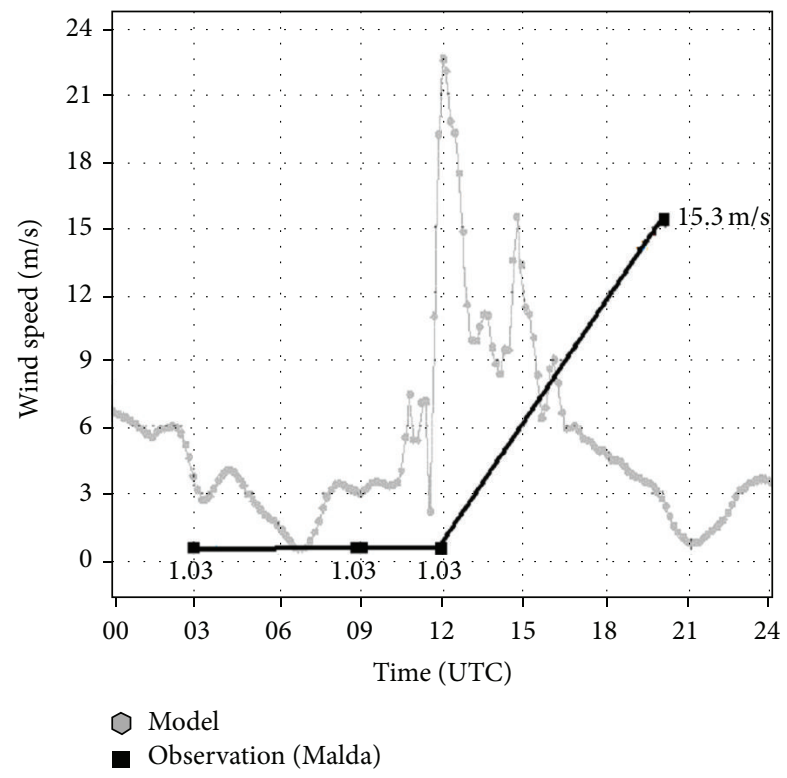

(c)

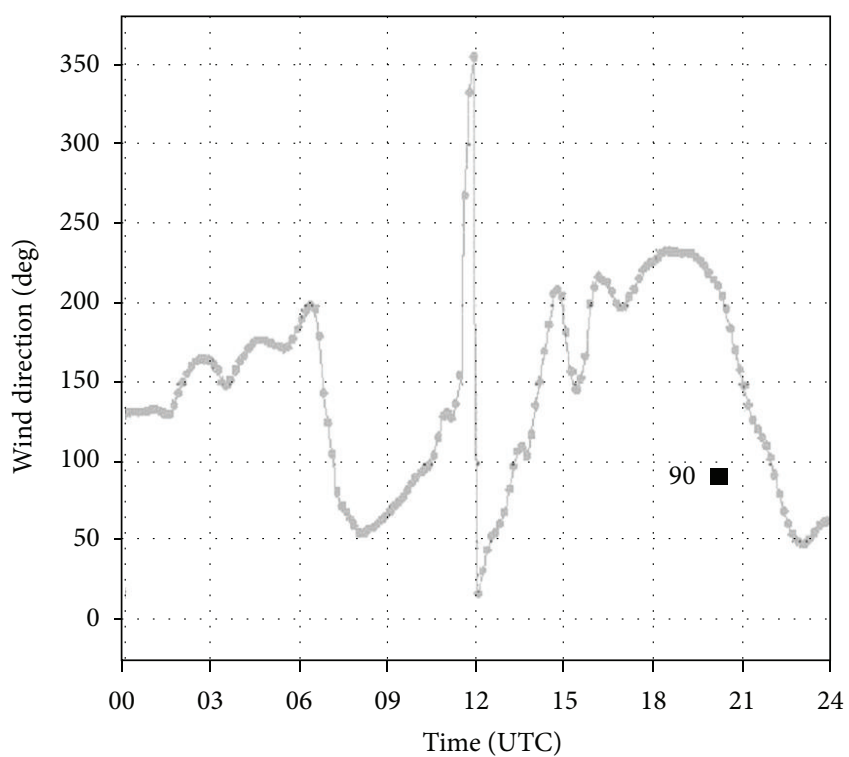

(b)

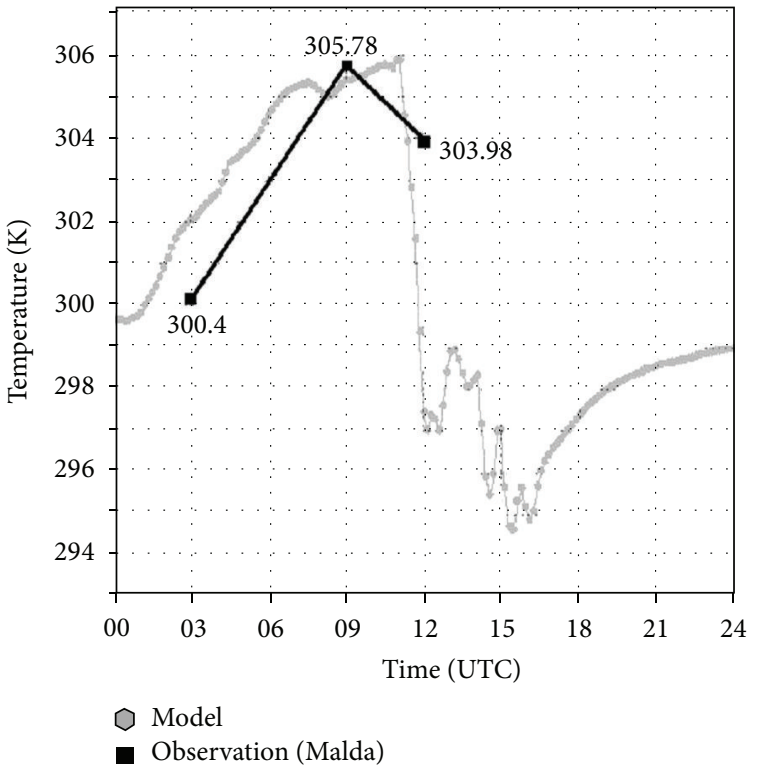

(d)

Figure 5: (a) Model derived surface pressure plot against time at 24.18 N, 88.60 E on April 10, 2006. (b) Model derived surface wind direction plot against time at $24.18 \mathrm{~N}, 88.60 \mathrm{E}$ on April 10, 2006. (c) Model derived surface wind speed plot against time at 24.18 N, $88.60 \mathrm{E}$ on April 10, 2006. (d) Model derived surface temperature plot against time at 23.0 N, 87.45 E on April 10, 2006.

According to Daily Weather Report of Indian Meteorological Department (IMD) the first one occurred on April 10,2006 . On that day heat wave prevailed at some places of the state of Jharkhand and interior Orissa. Maximum temperature rose from the previous day value in some portions of Sub-Himalayan West Bengal, Sikkim, Orissa, Bihar, and Jharkhand. Maximum temperature was above normal in Jharkhand, interior Orissa, and Bihar region. So a favourable environment for convective development was created. A wind squall occurred at Malda $\left(25.0^{\circ} \mathrm{N}, 88.13^{\circ} \mathrm{E}\right)$ from easterly direction with maximum wind speed of $15.3 \mathrm{~m} / \mathrm{s}$ at 2002 UTC on April 10, 2006, and lasted for 3 minutes only. On the other hand, hailstorm occurred at Srinikatan $\left(23.6^{\circ} \mathrm{N}\right.$, $87.7^{\circ} \mathrm{E}$ ) at $1132 \mathrm{UTC}$ on that day with maximum diameter of hail being $2 \mathrm{~cm}$. And it lasted for 2 to 3 minutes. As observed by IMD, Srinikatan had $20 \mathrm{~mm}$ of rainfall.

According to IMD, the second one occurred on April 13, 2006. On that day heat wave condition prevailed over Chota Nagpur Plateau region. Maximum temperature attained highest value at Jamshedpur $\left(22.49^{\circ} \mathrm{N}, 86.11^{\circ} \mathrm{E}\right)$, Gaya $\left(24.75^{\circ} \mathrm{N}, 84.95^{\circ} \mathrm{E}\right)$, Bhagalpur $\left(25.26^{\circ} \mathrm{N}, 86.98^{\circ} \mathrm{E}\right)$, and Daltongunge $\left(24.05^{\circ} \mathrm{N}, 84.06^{\circ} \mathrm{E}\right)$. Information of three wind 


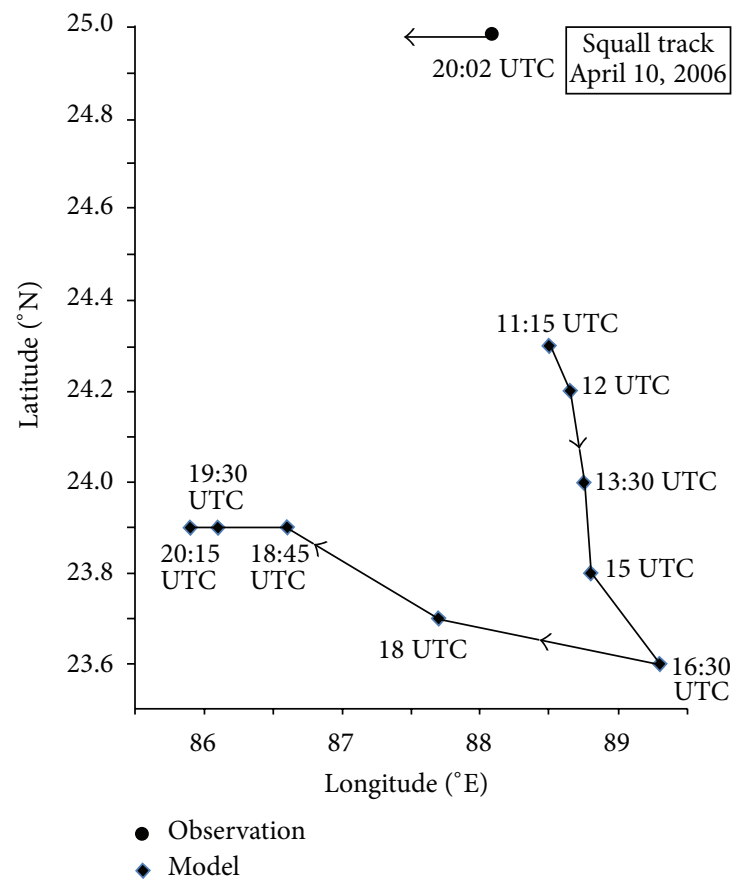

FIGURE 6: Wind squall track on April 10, 2006.

squalls striking different places of Gangetic West Bengal is available from IMD. The first wind squall struck Bankura at 0930 UTC and it lasted for 2 minutes. The maximum wind speed was noted as $22.22 \mathrm{~m} / \mathrm{s}$. The second wind squall struck Burdwan $\left(23.23^{\circ} \mathrm{N}, 87.85^{\circ} \mathrm{E}\right)$ at $1031 \mathrm{UTC}$ and it lasted for 1 minute. Maximum wind speed was $21.11 \mathrm{~m} / \mathrm{s}$. The third squall struck Krishnanagar $\left(23.40^{\circ} \mathrm{N}, 88.52^{\circ} \mathrm{E}\right)$ at $1222 \mathrm{UTC}$ to last for 1 minute only. Maximum wind speed was $20 \mathrm{~m} / \mathrm{s}$. All three squalls came from the northwest direction. This is a clear case of Nor'wester; the three concerned stations are almost aligned west to east and the propagating nature of the system is evident from the time sequence. Hailstorm was registered at Keonjhar $\left(21.6^{\circ} \mathrm{N}, 85.5^{\circ} \mathrm{E}\right)$ on that day from 0125 UTC to 0145 UTC from southwest direction and the hail diameter was $1 \mathrm{~cm}$. As observed by IMD, some of the places in Gangetic West Bengal like Diamond Harbour $\left(22.18^{\circ} \mathrm{N}, 88.20^{\circ} \mathrm{E}\right)$ had $17 \mathrm{~mm}$, Burdwan $15 \mathrm{~mm}$, Midnapore $\left(22.42^{\circ} \mathrm{N}, 87.32^{\circ} \mathrm{E}\right)$ had $13 \mathrm{~mm}$, and Alipore $\left(22.53^{\circ} \mathrm{N}, 88.33^{\circ} \mathrm{E}\right)$ had $8 \mathrm{~mm}$ of 24 -hour accumulated rainfall.

The third case occurred on April 18, 2006, as recorded in Daily Weather Report of IMD. On that day the maximum temperature fell from the previous day at most of the places in the states of West Bengal, Bihar, and Sikkim. A wind squall passed over Gaya $\left(24.75^{\circ} \mathrm{N}, 84.95^{\circ} \mathrm{E}\right)$ on that day at 1300 UTC from westerly direction with maximum wind speed of $16.1 \mathrm{~m} / \mathrm{s}$ and it lasted for 1 minute. Another squall passed over Malda at 1915 UTC on the same day from westerly direction with maximum wind speed of $15.6 \mathrm{~m} / \mathrm{s}$ for 1 minute. As observed by IMD, $60 \mathrm{~mm}$ rainfall was recorded at Malda.

On all three occasions thundershower was reported from some of the observatories of IMD located over the domain, though rain was insignificant on previous or after 24 hours.
Details of all the wind squalls are given in Table 3. Various regional locations mentioned in the literature are presented in Figure 1.

3.2. Synoptic Analysis. As synoptic condition has significant role in the generation of storm and the model output is sensitive to initial condition, it is important to see if the synoptic condition simulated by the model is similar to that observed. We first compare mean sea level pressure (MSLP) and temperature at the starting time of model run. The model was run from 1200 UTC of the previous day to 1200 UTC of the postday for each day of development. So, it was run from 1200 UTC of April 09, 2006, to 1200 UTC of April 11, 2006, for the study of severe local storm on April 10, 2006, and for the study of the other two cases; the model run was from 1200 UTC of April 12, 2006, to 1200 UTC of April 14, 2006, and 1200 UTC of April 17, 2006, to 1200 UTC of April 19, 2006, respectively.

Figures 2(a) and 2(b) show observed and model MSLP plot at time $t=0$ of time integration and Figures 2(c) and 2(d) stand for temperature plot for the same initial time, for the system occurring on April 10, 2006. Observed mean sea level pressure (MSLP) and temperature are produced from the data available from IMD observatories and the model parameters are available from NCEP fnl data. Figures 3(a), 3(b), 3(c), and 3(d) stand for the same parameters, respectively, for the system occurring on April 13, 2006. Similarly Figures 4(a) and 4(b) are MSLP plots at model initial time and Figures $4(\mathrm{c})$ and $4(\mathrm{~d})$ are temperature plots also at model initial time, for the system occurring on April 18, 2006. One can say the initial synoptic conditions described by MSLP and temperature for all three cases have reasonably similar pattern 


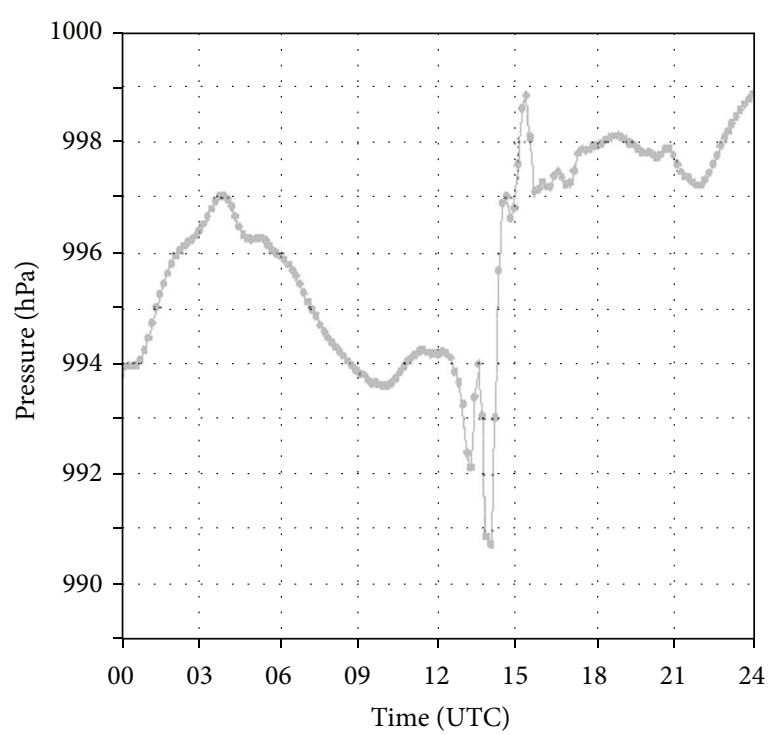

(a)

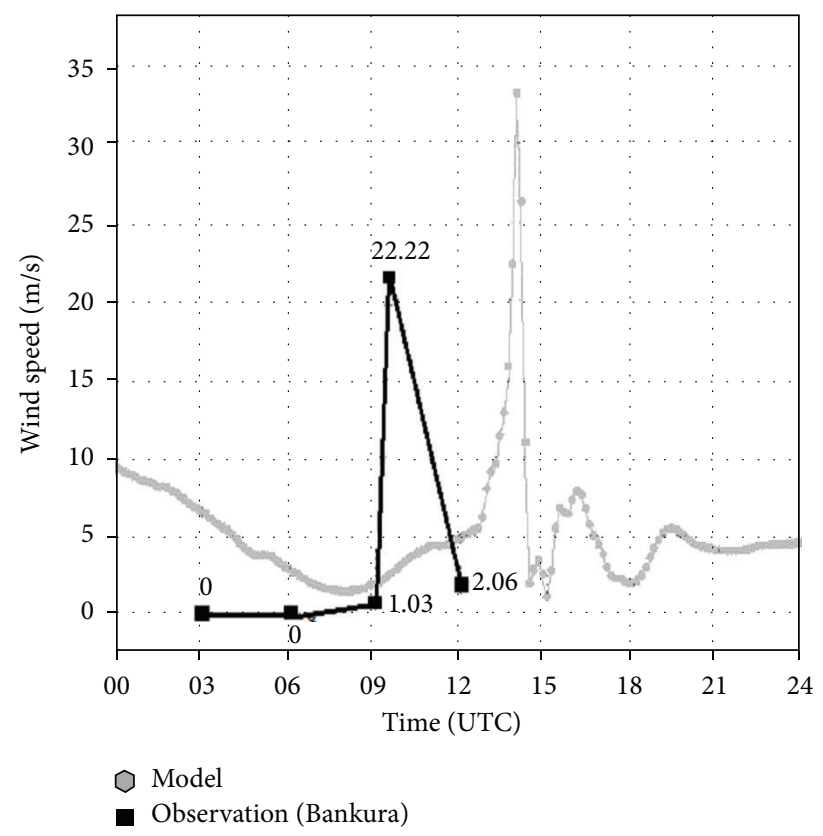

(c)

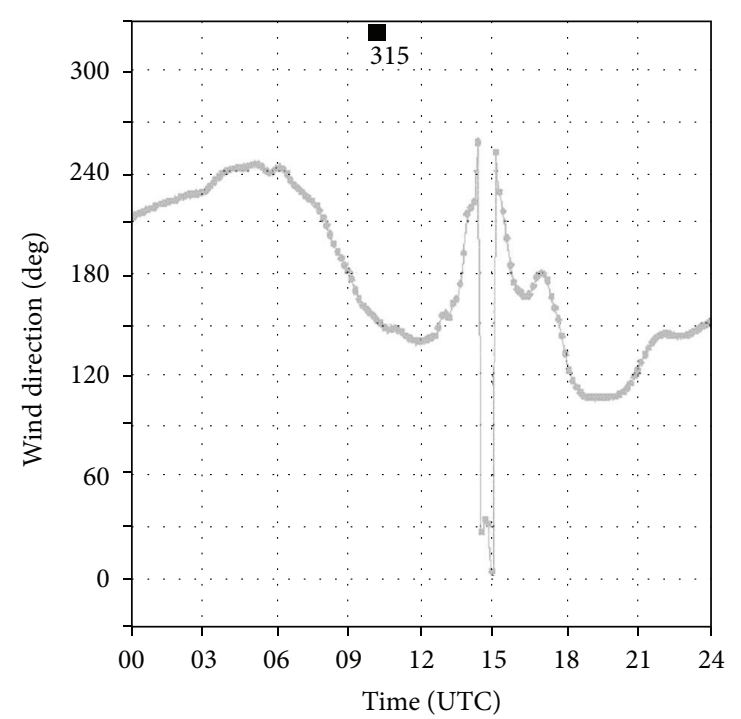

(b)

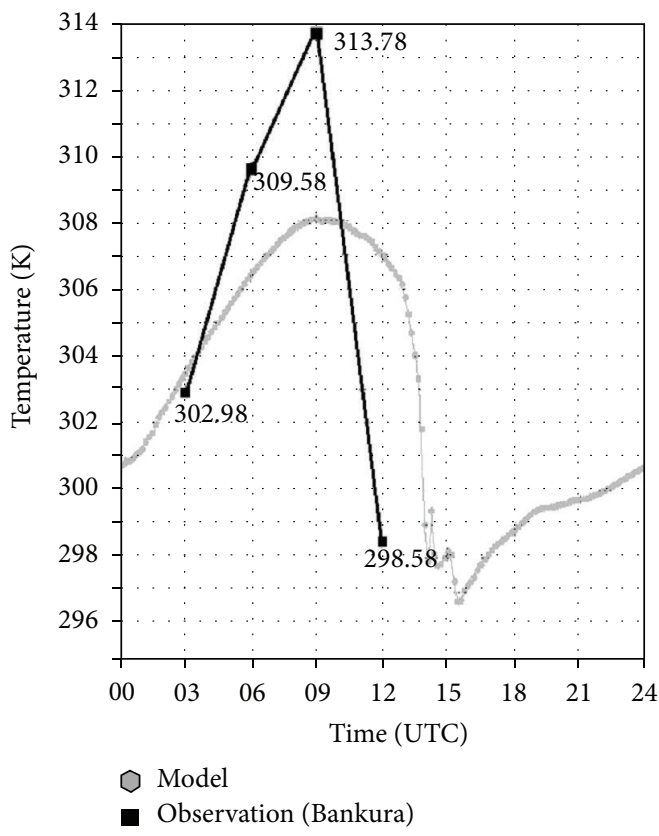

(d)

Figure 7: (a) Model derived surface pressure plot against time at 23.0 N, $87.45 \mathrm{E}$ on April 13, 2006. (b) Model derived surface wind direction plot against time at $23.0 \mathrm{~N}, 87.45 \mathrm{E}$ on April 13, 2006. (c) Model derived surface wind speed plot against time at 23.0 N, $87.45 \mathrm{E}$ on April 13, 2006. (d) Model derived surface temperature plot against time at $23.0 \mathrm{~N}, 87.45 \mathrm{E}$ on April 13, 2006.

for both model and observation, though there is some +ve and -ve biases which cannot be neglected. But observations through objective analysis are there to minimize these effects.

3.3. Wind Squall Analysis. We now attempt to check if the model simulated convective system in the present study exhibits the above mentioned sequence of changes in the meteorological parameters.

On April 10, 2006, the model could simulate the best presentation of the above mentioned features at a location with latitude and longitude as $24.18^{\circ} \mathrm{N}, 88.6^{\circ} \mathrm{E}$ at a time close to 1200 UTC. The corresponding figures are given in Figures 5(a), 5(b), 5(c), and 5(d). As per records from IMD a wind squall occurred at Malda $\left(25.0^{\circ} \mathrm{N}, 88.13^{\circ} \mathrm{E}\right)$ at 2002 UTC and a hailstorm struck Sriniketan $\left(23.6^{\circ} \mathrm{N}, 87.7^{\circ} \mathrm{E}\right)$ at 1132 UTC. So the model could simulate a wind squall at a place between Malda and Sriniketan, but more eastward. Simulated place is $104 \mathrm{Km}$ southeast of Malda and $118 \mathrm{Km}$ northeast of Sriniketan. However, the simulated time of the system is almost coincident with the time of occurrence of the hailstorm at Sriniketan. 


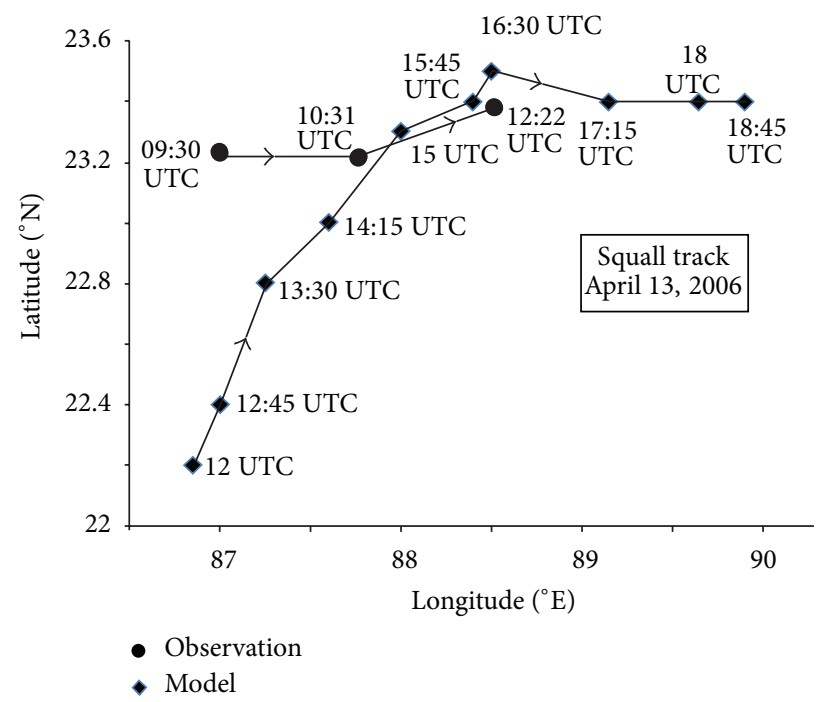

FIgUre 8: Wind squall track on April 13, 2006.

TABle 3: Nor'westers.

\begin{tabular}{|c|c|c|c|c|c|c|c|}
\hline Date & Squall location & $\begin{array}{c}\text { Time of } \\
\text { occurrence }\end{array}$ & $\begin{array}{l}\text { Maximum } \\
\text { wind speed }\end{array}$ & Direction & Duration & Hail information & Hail location \\
\hline April 10, 2006 & $\begin{array}{l}\text { Malda } \\
\left(25.0^{\circ} \mathrm{N}, 88.13^{\circ} \mathrm{E}\right)\end{array}$ & 2002 UTC & $15.3 \mathrm{~m} / \mathrm{s}$ & From easterly & 3 minutes & $\begin{array}{l}\text { Occurred at } 1132 \text { UTC } \\
\text { with maximum diameter } \\
2 \mathrm{~cm} \text { and lasted for } 2 \text { to } 3 \\
\text { minutes }\end{array}$ & $\begin{array}{l}\text { Srinitekan } \\
\left(23.6^{\circ} \mathrm{N}\right. \\
\left.87.7^{\circ} \mathrm{E}\right)\end{array}$ \\
\hline \multirow{3}{*}{ April 13, 2006} & $\begin{array}{l}\text { Bankura } \\
\left(23.25^{\circ} \mathrm{N}, 87.05^{\circ} \mathrm{E}\right)\end{array}$ & 0930 UTC & $22.22 \mathrm{~m} / \mathrm{s}$ & $\begin{array}{l}\text { From north-west } \\
\text { direction }\end{array}$ & 2 minutes & \multirow{3}{*}{$\begin{array}{l}\text { Occurred during } 0125 \\
\text { UTC to } 0145 \text { UTC from } \\
\text { southwest direction with } \\
\text { maximum hail diameter } \\
1 \mathrm{~cm}\end{array}$} & \multirow{3}{*}{$\begin{array}{l}\text { Keonjhar } \\
\left(21.6^{\circ} \mathrm{N}\right. \\
\left.85.5^{\circ} \mathrm{E}\right)\end{array}$} \\
\hline & $\begin{array}{l}\text { Burdwan } \\
\left(23.23^{\circ} \mathrm{N}, 87.85^{\circ} \mathrm{E}\right)\end{array}$ & 1031 UTC & $21.11 \mathrm{~m} / \mathrm{s}$ & $\begin{array}{l}\text { From north-west } \\
\text { direction }\end{array}$ & 1 minute & & \\
\hline & $\begin{array}{l}\text { Krishnanagar } \\
\left(23.40^{\circ} \mathrm{N}, 88.52^{\circ} \mathrm{E}\right)\end{array}$ & 1222 UTC & $20 \mathrm{~m} / \mathrm{s}$ & $\begin{array}{l}\text { From north-west } \\
\text { direction }\end{array}$ & 1 minute & & \\
\hline \multirow{2}{*}{ April 18, 2006} & $\begin{array}{l}\text { Gaya } \\
\left(24.75^{\circ} \mathrm{N}, 84.95^{\circ} \mathrm{E}\right)\end{array}$ & 1300 UTC & $16.1 \mathrm{~m} / \mathrm{s}$ & $\begin{array}{l}\text { From westerly } \\
\text { direction }\end{array}$ & 1 minute & \multirow{2}{*}{ No hailstorm record } & \\
\hline & $\begin{array}{l}\text { Malda } \\
\left(25.0^{\circ} \mathrm{N}, 88.13^{\circ} \mathrm{E}\right)\end{array}$ & 1915 UTC & $15.6 \mathrm{~m} / \mathrm{s}$ & $\begin{array}{l}\text { From westerly } \\
\text { direction }\end{array}$ & 1 minute & & \\
\hline
\end{tabular}

From Figure 5(a) the pressure rises to a level of $997.75 \mathrm{hpa}$ at 1200 UTC starting from $994.50 \mathrm{hpa}, 27$ minutes prior, and the pressure stays at that level for the next 9 minutes. The wind makes a shift of 200 degrees, from 155 degrees to 355 degrees within the same 27 minutes' interval (Figure 5(b)). Within the same interval wind speed rises from $2.25 \mathrm{~m} / \mathrm{s}$ to $22.5 \mathrm{~m} / \mathrm{s}$ (Figure 5(c)). The temperature drops steadily from $306 \mathrm{~K}$ to $297.4 \mathrm{~K}$ at 1200 UTC starting from 54 minutes prior to it (Figure 5(d)). Propagation path of the wind squall is plotted in Figure 6 which shows that the simulated squall was from northerly and then turns towards west and become from easterly as observed at Malda though temporal and spatial mismatch exist. The location of model simulation is also associated with rain. Rain with significant intensity starts from 1133 UTC and, within the next 27 minutes, $67.5 \mathrm{~mm}$ of rain occurs at the location in question. Beyond 1200 UTC, rain has sufficient intensity in the next 18 minutes.
So, the pressure rise, wind shift and surge, and significant precipitation rate are simultaneous as per the model simulation. Now sudden temperature fall, pressure rise, and sharp wind speed rise indicate strong downdraft reaching the ground which is the cause of wind squall. However, the temperature drop starts even before the beginning of the above mentioned four events.

On April 13, 2006, the best simulation of a wind squall was noted at $23.0^{\circ} \mathrm{N}, 87.45^{\circ} \mathrm{E}$, whereas information of three wind squalls was available from IMD as stated in Section 4. In addition, hailstorm was noted at Keonjhar $\left(21.6^{\circ} \mathrm{N}, 85.5^{\circ} \mathrm{E}\right)$ for 20 minutes starting from 0125 UTC. The time sequences of model simulation for best wind squall situation are given in Figures 7(a), 7(b), 7(c), and 7(d) in case of pressure rise, wind shift, wind surge, and temperature drop, respectively. One can note from Figure 7(a) that the pressure rises from $990.3 \mathrm{hpa}$ to $996.8 \mathrm{hpa}$ during the interval 1357 UTC to 1424 UTC. Wind shift occurs in the next 9 minutes, that is, 1424 UTC 


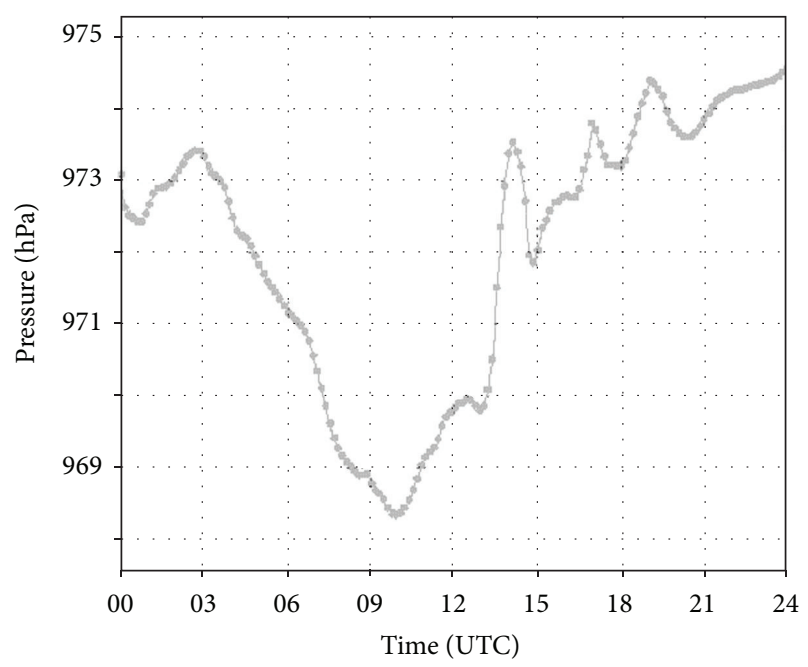

(a)

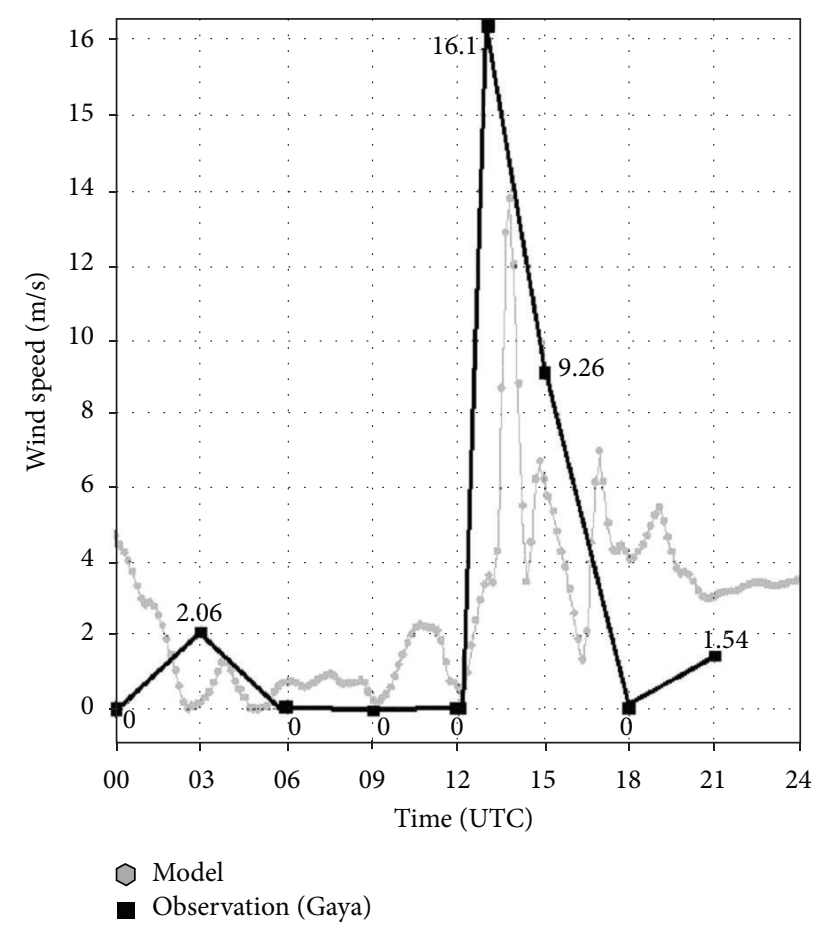

(c)

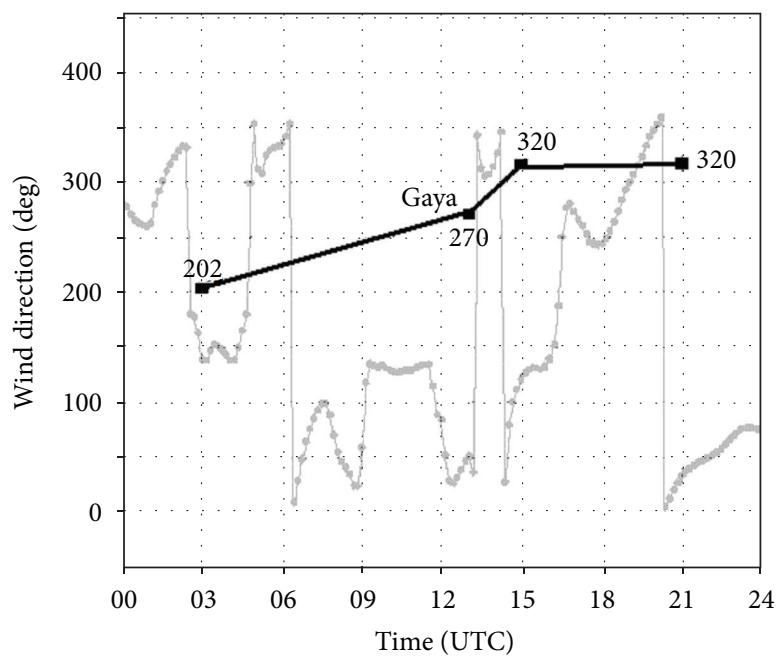

(b)

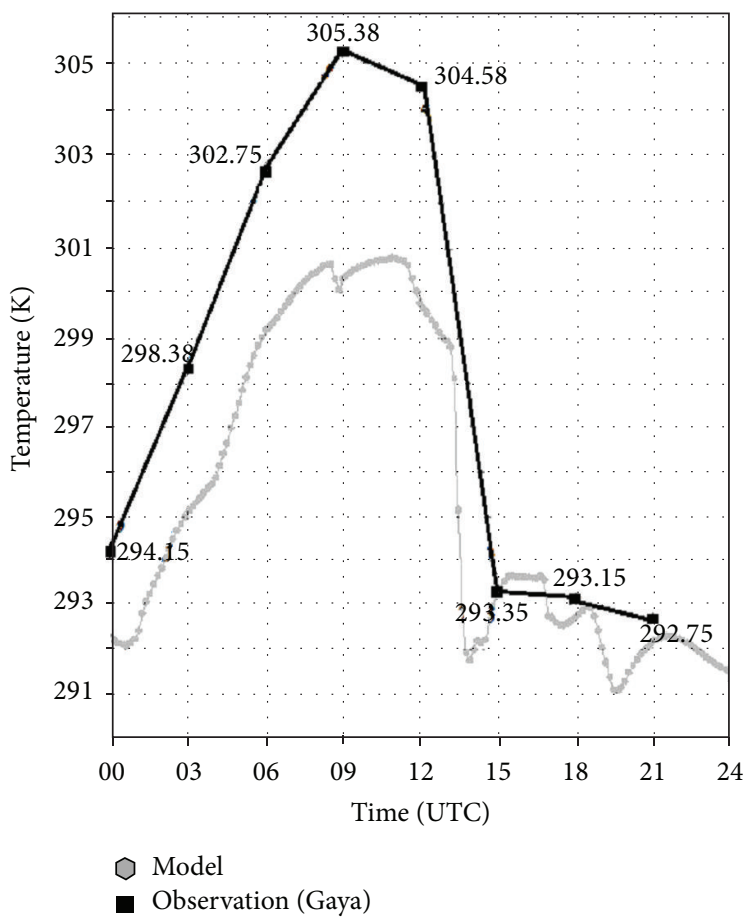

(d)

Figure 9: (a) Model derived surface pressure plot against time at 23.65 N, $85.65 \mathrm{E}$ on April 18, 2006. (b) Model derived surface wind direction plot against time at $23.65 \mathrm{~N}, 85.65 \mathrm{E}$ on April 18, 2006. (c) Model derived surface wind speed plot against time at 23.65 N, $85.65 \mathrm{E}$ on April 18, 2006. (d) Model derived surface temperature plot against time at 23.65 N, 85.65 E on April 18, 2006.

to $1433 \mathrm{UTC}$, from $249^{\circ}$ to $26^{\circ}$ (Figure $7(\mathrm{~b})$ ). Wind surges to $33 \mathrm{~m} / \mathrm{s}$ from $16 \mathrm{~m} / \mathrm{s}$ in a span of 18 minutes starting from 1339 UTC (Figure 7(c)). The temperature drops from $301.8 \mathrm{~K}$ to $299.0 \mathrm{~K}$ in a span of 9 minutes starting from 1348 UTC (Figure 7(d)). Propagation path of the wind squall is plotted in Figure 8 which shows that the simulated squall was from south-westerly direction. It originates at 12 UTC and moves towards northeast and at 1630 UTC it turns towards east. The squall was observed to move almost towards east exposing some temporal and spatial mismatch. Rain associated with the simulated system is neither significant nor continuous. From 1348 UTC to 1406 UTC, only $0.28 \mathrm{~mm}$ of rain is simulated and between 1415 UTC and 1424 UTC only $0.26 \mathrm{~mm}$ of rain is simulated.

In this case the model simulated events have a different sequence. At first, the wind surges, then comes sharp temperature drop, and pressure rise occurs thereafter. Wind shift occurs at the last. Rain starts even before the advent of wind surge. These are the indications of existence of wind squall simulated by the model. 


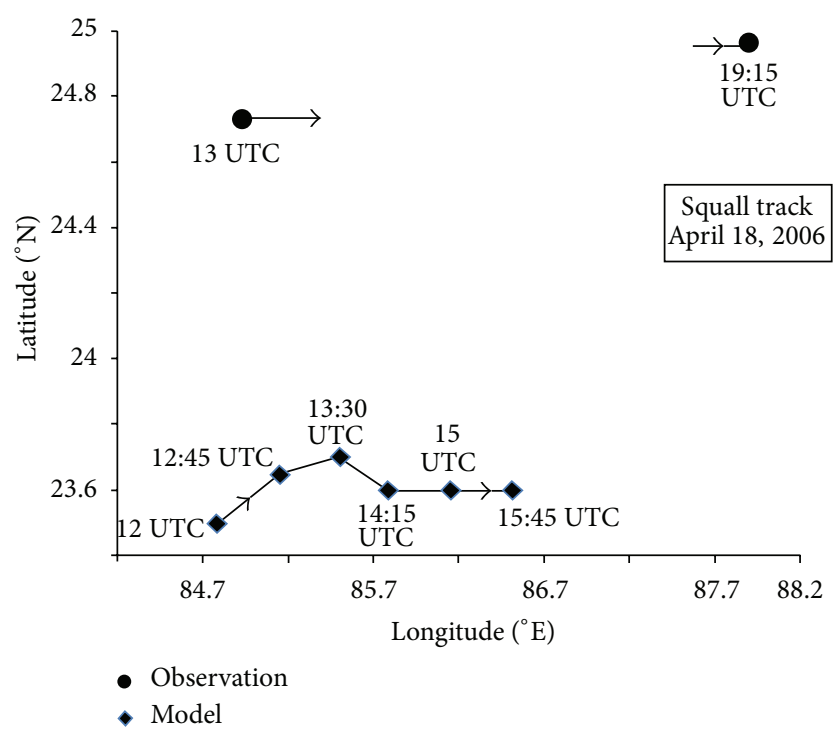

FIGURE 10: Wind squall track on April 18, 2006.

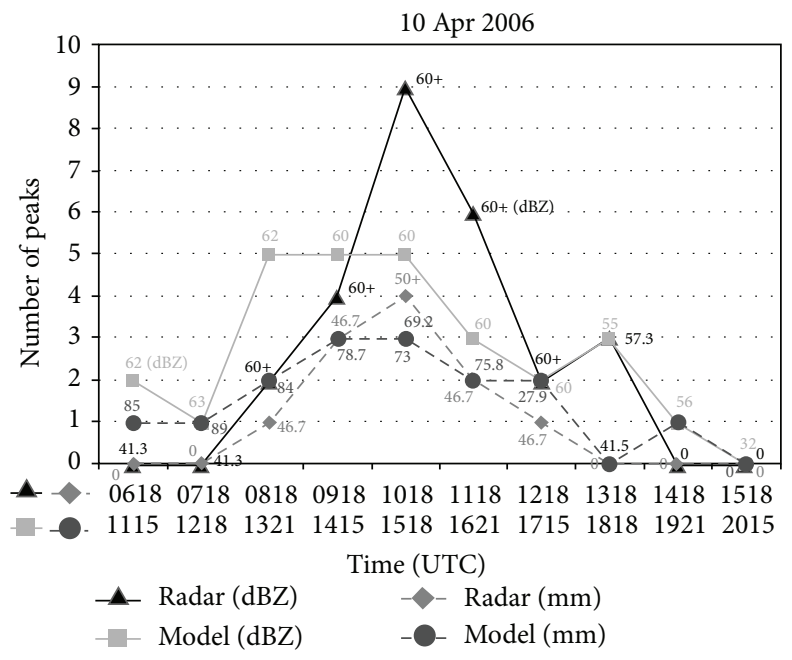

FIGURE 11: Plots of number of peaks of $\operatorname{Max}(\mathrm{Z})$ and reflectivity from model and that of VIL and IRW at different time on April 10, 2006.

On April 18, 2006, two wind squalls were reported by IMD, but both the squalls are weak. The best simulation by the model occurs at $23.65^{\circ} \mathrm{N}, 85.65^{\circ} \mathrm{E}$. The squall observed at Gaya $\left(24.75^{\circ} \mathrm{N}, 84.9^{\circ} \mathrm{E}\right)$ occurs at $1300 \mathrm{UTC}$ and the other one strikes Malda $\left(25.0^{\circ} \mathrm{N}, 88.13^{\circ} \mathrm{E}\right)$ at $1915 \mathrm{UTC}$. The time and place of wind squall simulation is closer to Gaya.

The time sequences of model simulation for pressure rise, wind shift, wind surge, and temperature drop are given in Figures 9(a), 9(b), 9(c), and 9(d). The pressure rises steadily from $969.8 \mathrm{hpa}$ to $979.6 \mathrm{hpa}$ in a span of 63 minutes, starting from 1303 UTC (Figure 9(a)). One can see from Figure 9(b) there are a number of wind shifts. During the first wind shift, the direction changes from $27^{\circ}$ to $140^{\circ}$ in a span of 27 minutes starting from 0853 UTC, the next one occurs at 1133 UTC, and the wind direction changes from $140^{\circ}$ to $30^{\circ}$ in 45 minutes. In case of third wind shift, the direction changes from $40^{\circ}$ to $348^{\circ}$ during 1312 UTC to 1321 UTC; the last wind shift occurs at $1415 \mathrm{UTC}$ and the direction changes from $349^{\circ}$ to $25^{\circ}$ in a span of 9 minutes. Of the four wind shifts, the third one seems to have best relation with the present study.

The wind surges from $4.5 \mathrm{~m} / \mathrm{s}$ to $13.8 \mathrm{~m} / \mathrm{s}$ within a span of 27 minutes starting from 1321 UTC (Figure 9(c)). The temperature drops from $298.8 \mathrm{~K}$ to $291.9 \mathrm{~K}$ within the period 1312 UTC to 1348 UTC (Figure 9(d)). Propagation path of the wind squall is plotted in Figure 10 which shows that the simulated squall was initially from south-westerly direction. It originates at 12 UTC and moves towards northeast and turns twice and at 1415 UTC it moves towards east. The squall was discretely observed to move almost towards east at Gaya and Malda and thus exposing small temporal and but larger spatial mismatch. Significant rain starts from 1330 UTC and it continues up to 1424 UTC. Within 54 minutes $27.59 \mathrm{~mm}$ of rain is simulated.

At first the pressure rise takes place, the temperature drops, and wind shift follows it simultaneously in the next 


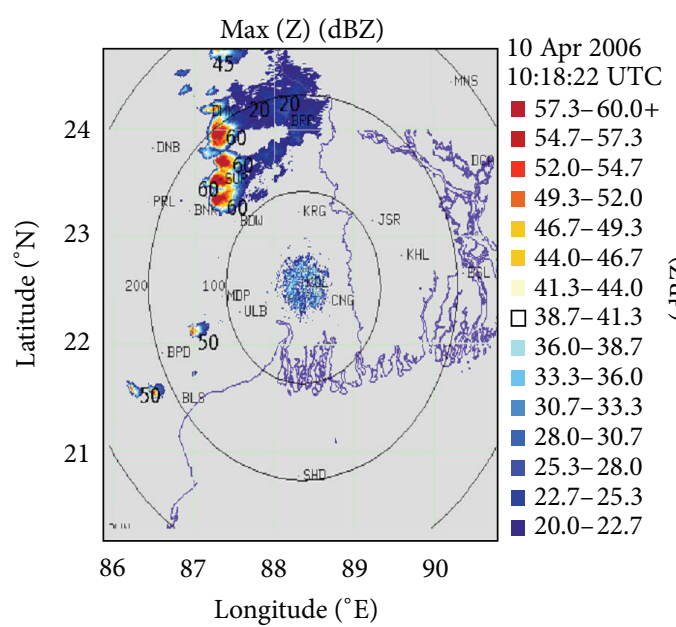

(a)

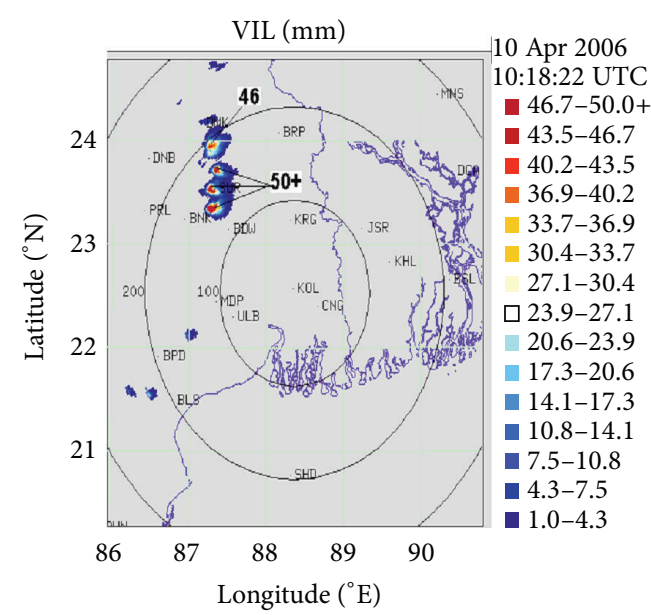

(c)

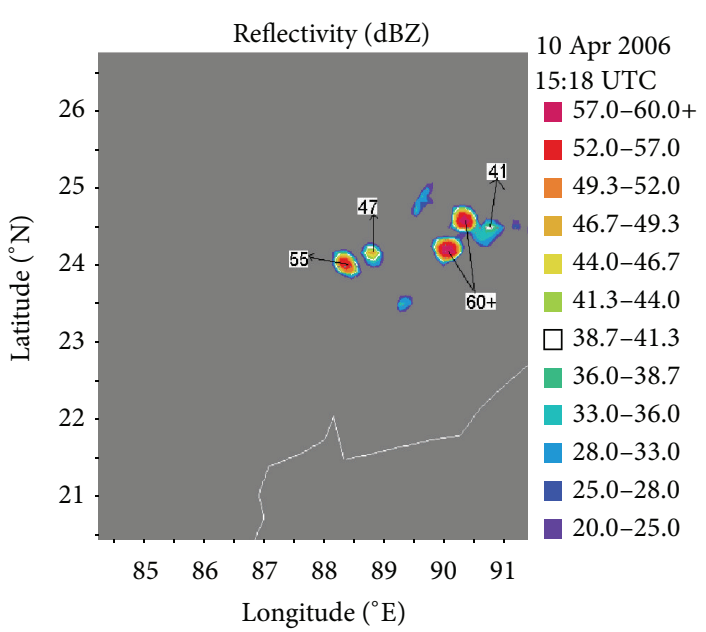

(b)

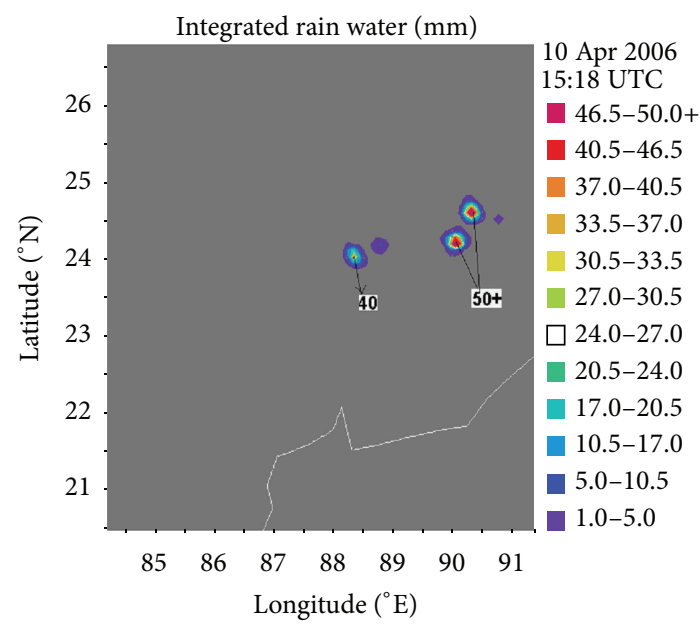

(d)

Figure 12: (a) Radar picture of $\operatorname{Max}(Z)$ at 1018 UTC on April 10, 2006. (b) Model reflectivity at 1518 UTC on April 10, 2006. (c) Radar VIL at 1018 UTC on April 10, 2006. (d) Model IRW at 1518 UTC on April 10, 2006.

time step, and the wind surges in the very next time step. Significant rain starts 9 minutes later. All these sudden changes are similar with the changes occurring at the time of passing of a wind squall.

One can clearly see that all the features of wind squall are present in all three simulations being presented here.

3.4. Comparison with Radar Observations. In all three cases, attempt has been made to match the maximum number of $\operatorname{Max}(\mathrm{Z})$ patch, a DWR product with the maximum number of model reflectivity cloud patches above a cut-off value. A similar approach has been made between the vertically integrated liquid (VIL) water in case of radar observation and integrated rain water (IRW) in case of the model.

At first let us consider the situation on April 10, 2006. From Figure 11, one can find that $\operatorname{Max}(Z)$ has highest number (9) of cloud patches above $42 \mathrm{dBZ}$ cut-off limit and that occurs at 1018 UTC. On the other hand, model reflectivity has highest number (5) of cloud patches above $42 \mathrm{dBZ}$ cut-off limit at 1518 UTC. The two patterns are taken as equivalent on the basis of highest number of reflecting cloud patches from observation and model. So, there exists a forward time-lag of almost five hours between radar observation and model output. Let us now look at the distribution of cloud patches. Previous work of the author [18] showed that this model can simulate the observed cloud patch both for weak and for strong systems which include dry convective system during March and such system during humid May. But temporal and spatial mismatch exist. The present study with such systems in almost dry environment also shows that the model is successful in capturing the cloud pattern with same weakness. Here the output has undergone a shift towards the east. The patches from the model also have propagation towards the eastern direction with time, like the cloud patches in radar observation. This time the model fails to simulate weak cells in this case. Two representative figures are presented here, one for radar reflectivity $\operatorname{Max}(\mathrm{Z})$ at $1018 \mathrm{UTC}$ (Figure 12(a)) and the other for model reflectivity at 1518 UTC (Figure 12(b)) for having a look at the magnitude of spatial shift. Propagation 


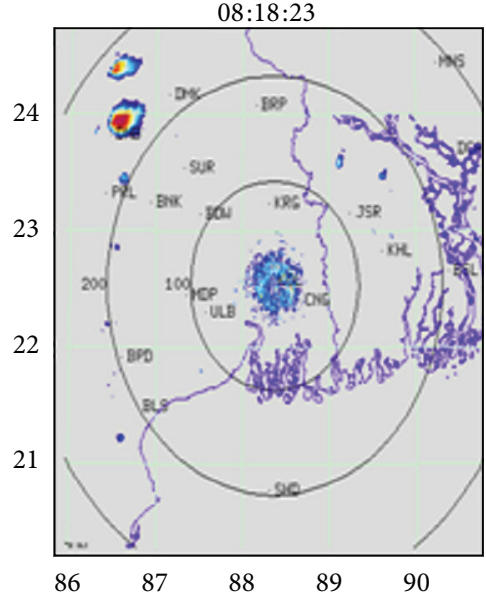

(a)

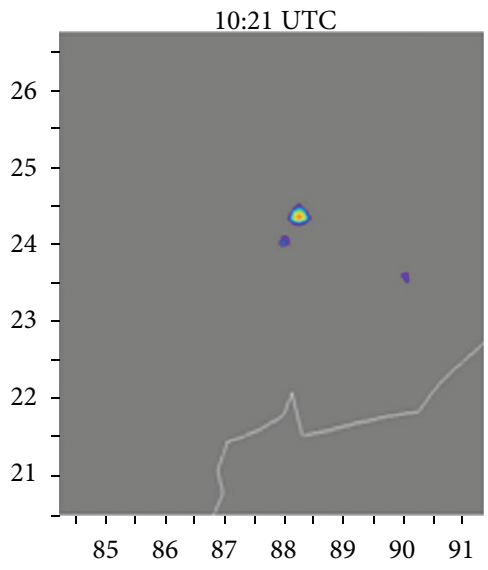

(d)

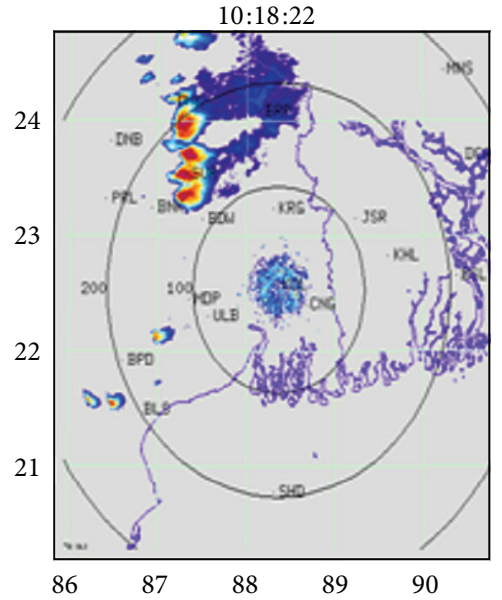

(b)

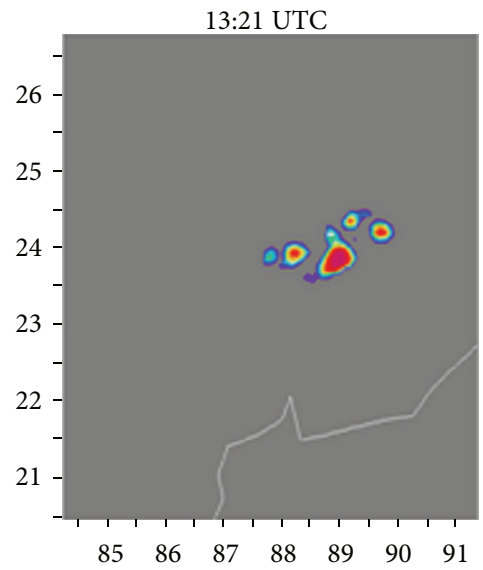

(e)

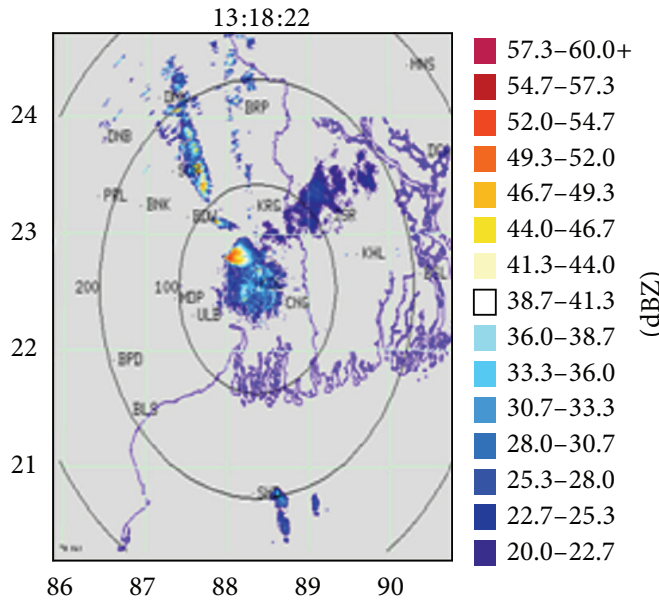

(c)

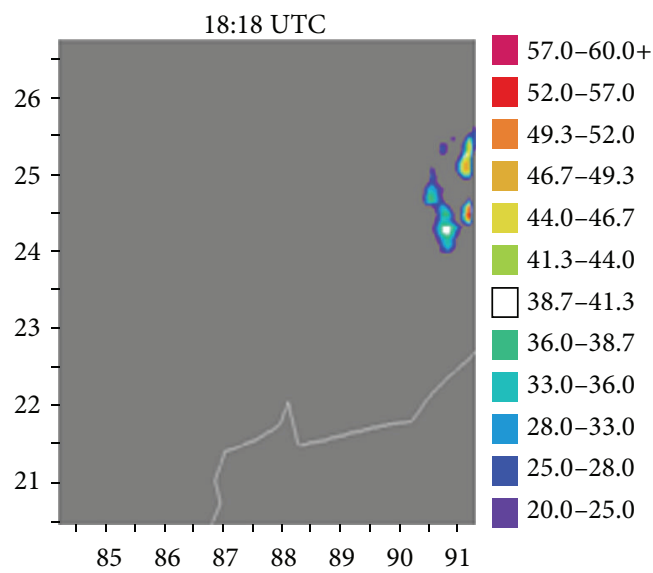

(f)

FIgURE 13: Propagation of the storm on April 10, 2006, as seen from $\operatorname{Max}(Z)$ and model simulated reflectivity pictures.

of the system from initial stage to diminishing stage as seen from radar picture and model simulation is given in Figure 13.

Next, let us consider a comparative study between VIL and IRW (Figure 11). Incidentally, the maximum number of cloud patches above an identical cut-off value of $40 \mathrm{~mm}$ of liquid water in both the cases occur at the same times like the previous case, that is, 1018 UTC for VIL and 1518 UTC for IRW. Two representative figures (Figures 12(c) and 12(d)) are being given here, one for VIL at 1018 UTC and the other for IRW at 1518 UTC.

Next, let us consider the development on April 13, 2006. From Figure 14, one can find that the maximum number of cloud patches (11) for radar reflectivity above the cut-off limit ( $40 \mathrm{dBZ}$ ) occurs at 1123 UTC, whereas the model reflectivity produces maximum number of patches (9) above an identical cut-off limit at 1527 UTC. So, there is a forward time-lag of about four hours between the radar and model reflectivity. Figures 15(a) and 15(b) show that the model is successful in capturing the cloud pattern with the same weakness as previously found.

Keeping the above mentioned time-lag, a comparative pattern of VIL and IRW response is given in Figure 14 in case of the developments of April 13, 2006, with a cut-off value of both VIL and IRW taken as $42.6 \mathrm{~mm}$. The patches for VIL have consistency with those of $\operatorname{Max}(\mathrm{Z})$ and the nature of movement is also similar. In case of IRW, number of cloud patches with low liquid water content is more than what is found in DWR picture. Two representative figures for VIL and IRW are being presented in Figures 15(c) and 15(d) for the developments at 1123 UTC and 1527 UTC, respectively. In this case, the propagation of the system from initial stage to diminishing stage as seen from radar picture and model simulation is given in Figure 16.

At the end, let us present our study for the developments occurring on April 18, 2006. To make best match with model products with cut-off limit $44 \mathrm{dBZ}$ for $\operatorname{Max}(\mathrm{Z})$ and $40 \mathrm{dBZ}$ for model reflectivity (Figure 17), now DWR product should have a forward lag of nearly 2 hours compared to the model product. As noted from DWR, initial development at 1150 UTC occurs in the north of Kolkata. With time, number of patches in the west increases and a distinct squall-line appears at 1650 UTC. Two figures are being presented (Figures 18(a) and $18(\mathrm{~b}))$ for $\operatorname{Max}(\mathrm{Z})$ at 1850 UTC and model reflectivity at 1648 UTC. The model reflectivity attains above $50 \mathrm{dBZ}$ only 


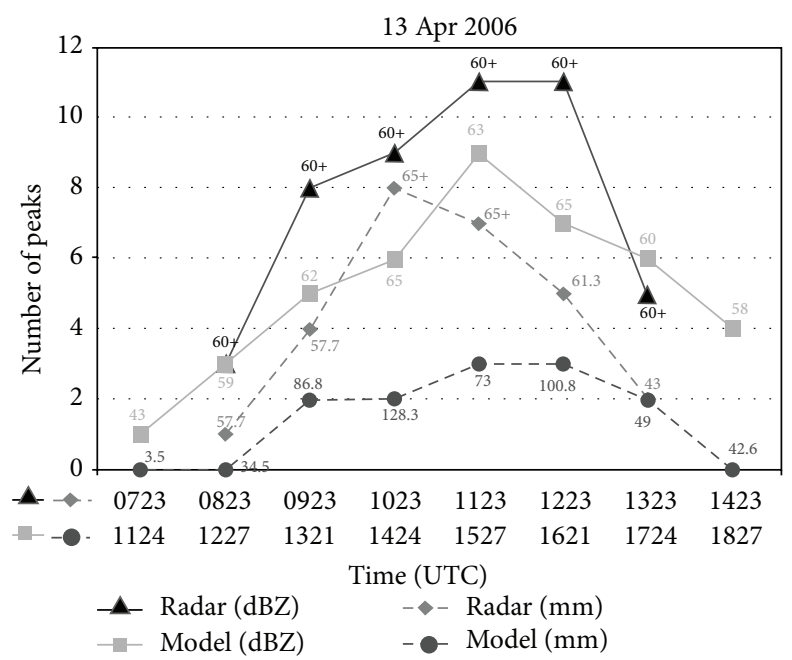

FIGURE 14: Plots of number of peaks of $\operatorname{Max}(Z)$ and reflectivity from model and that of VIL and IRW at different time on April 13, 2006.

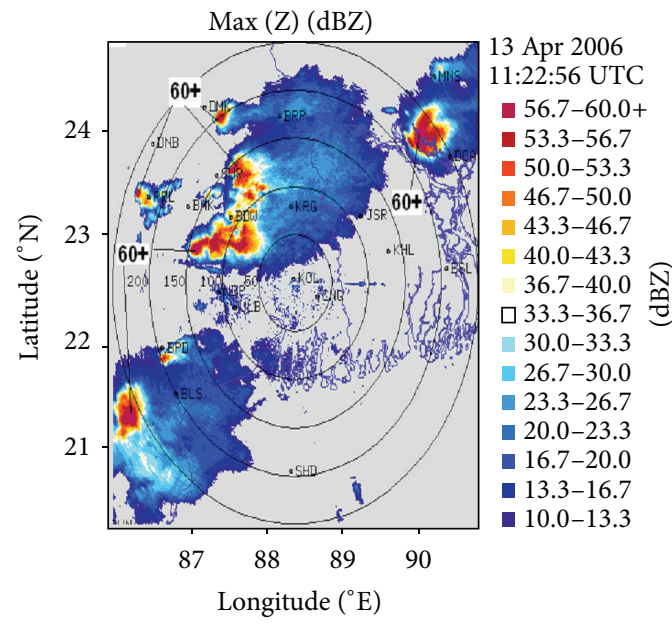

(a)

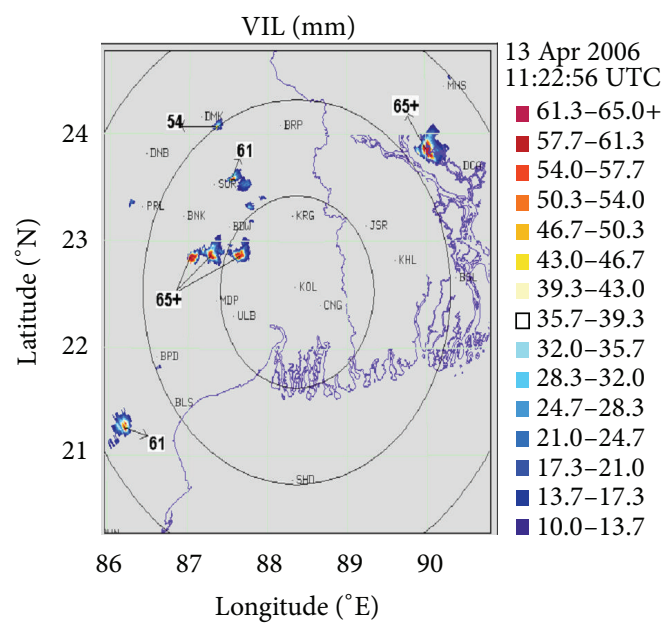

(c)

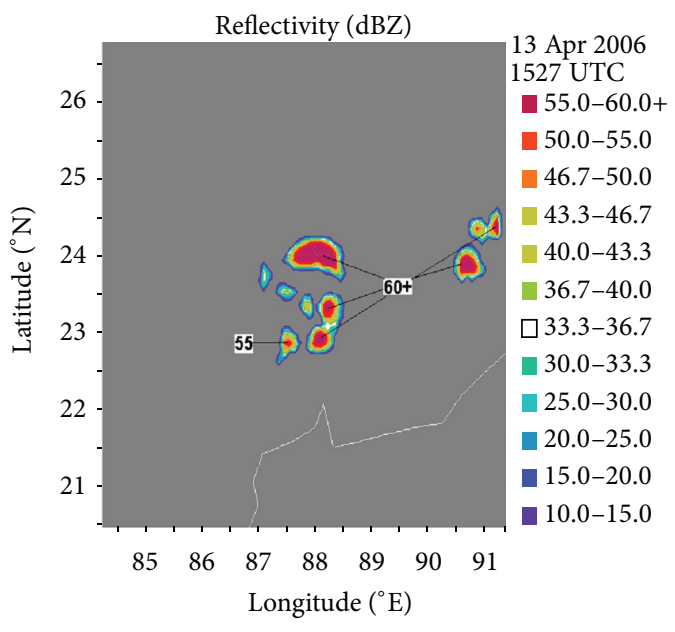

(b)

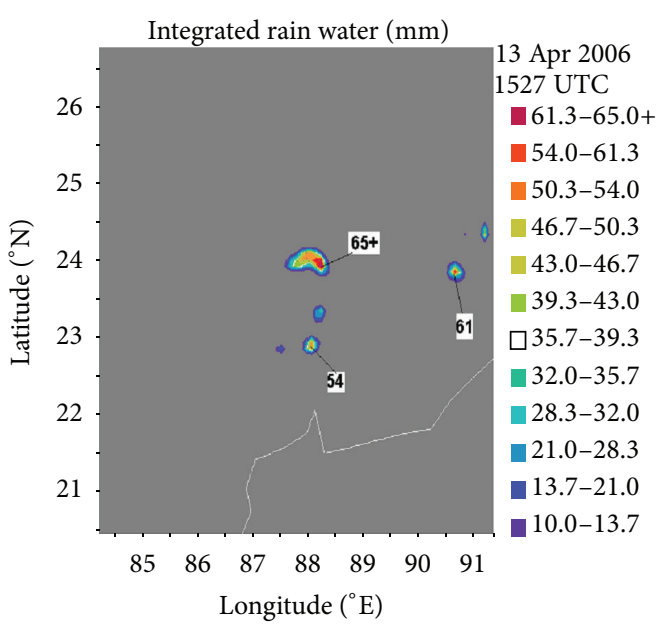

(d)

FIgUre 15: (a) Radar picture of $\operatorname{Max}(\mathrm{Z})$ at 1123 UTC on April 13, 2006. (b) Model reflectivity at 1527 UTC on April 13, 2006. (c) Radar VIL at 1123 UTC on April 13, 2006. (d) Model IRW at 1527 UTC on April 13, 2006. 


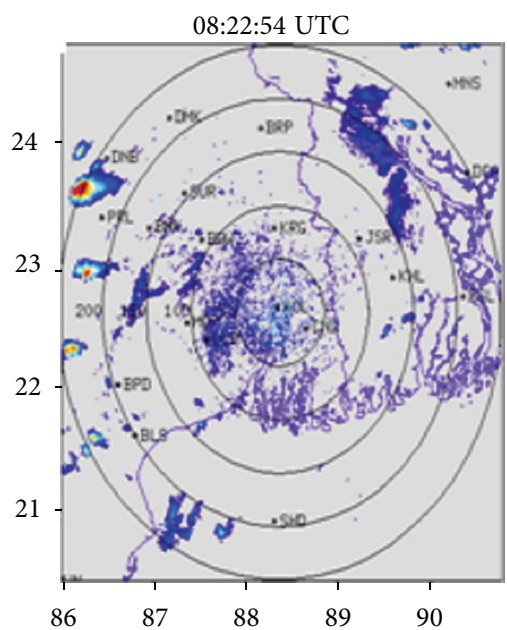

(a)

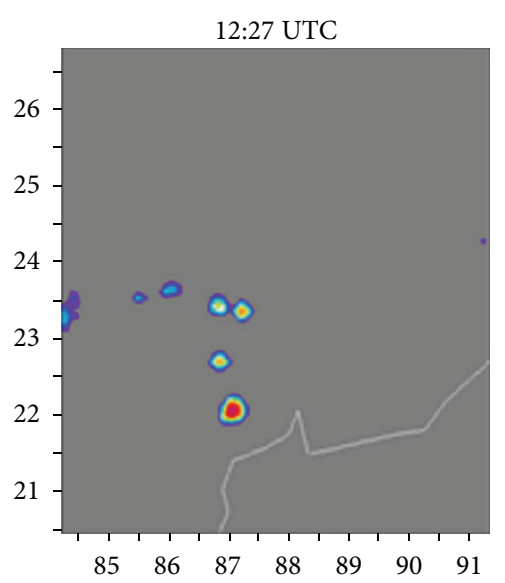

(d)

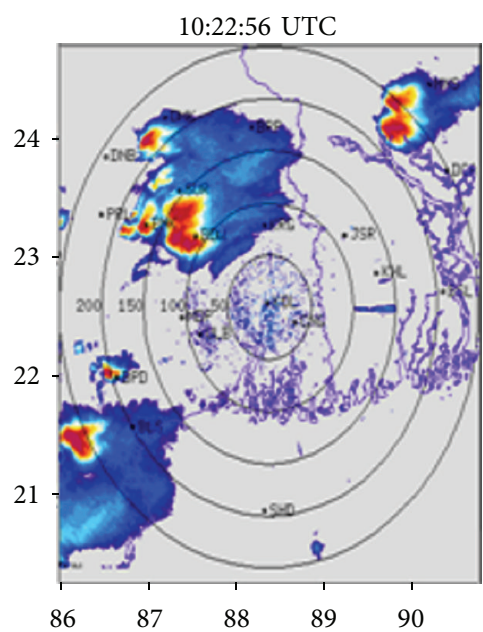

(b)

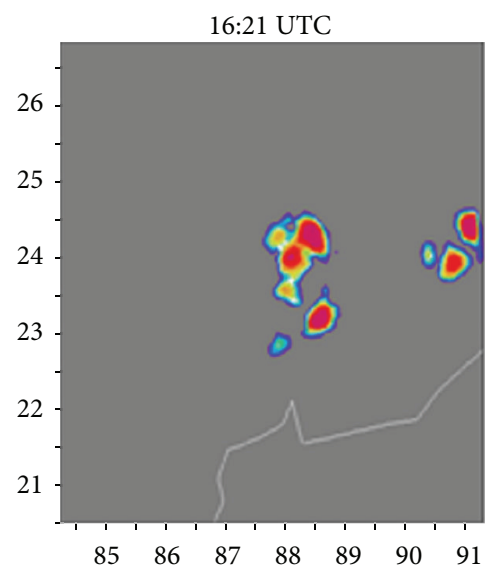

(e)

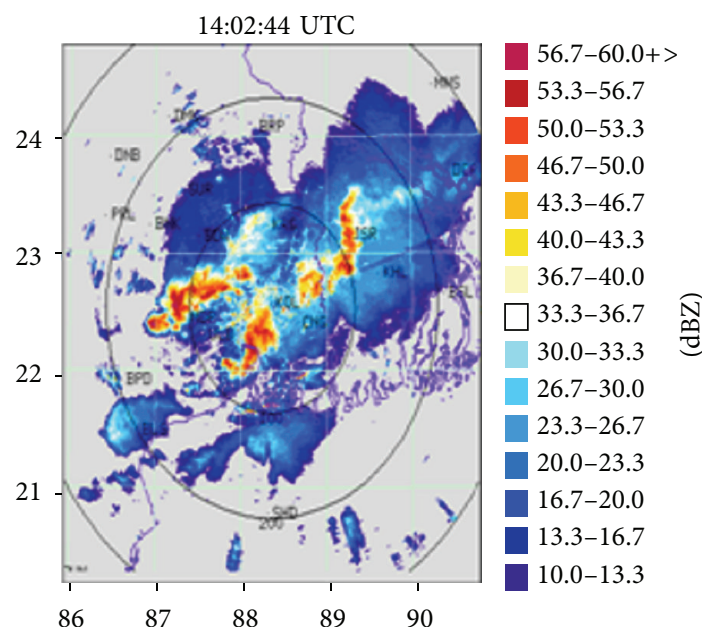

(c)

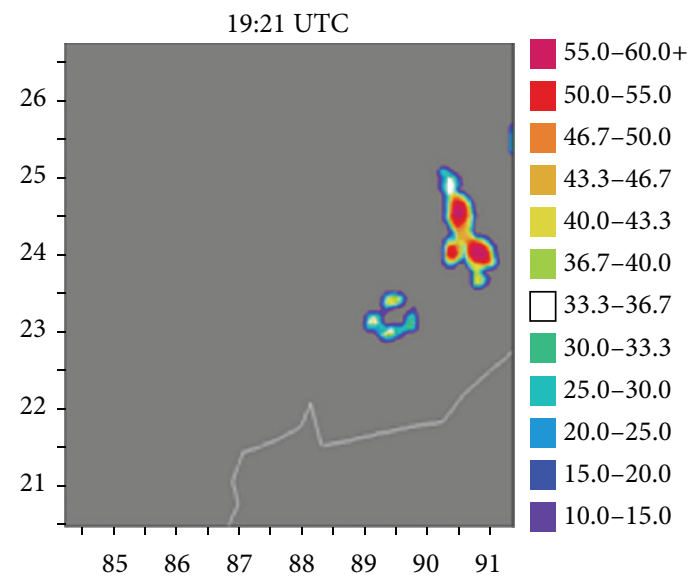

(f)

FIGURE 16: Propagation of the storm on April 13, 2006, as seen from $\operatorname{Max}(Z)$ and model simulated reflectivity pictures.

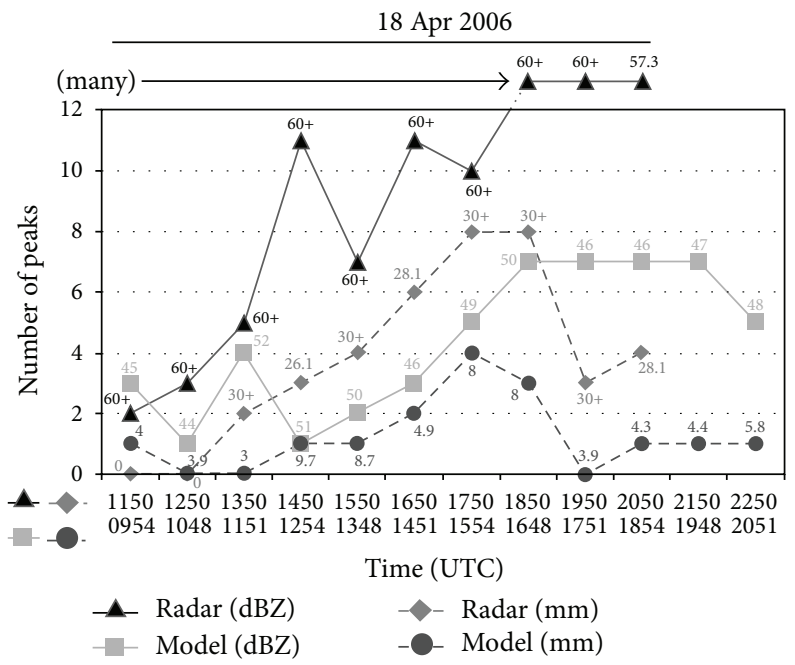

FIGURE 17: Plots of number of peaks of $\operatorname{Max}(Z)$ and reflectivity from model and that of VIL and IRW at different time on April 18, 2006. 


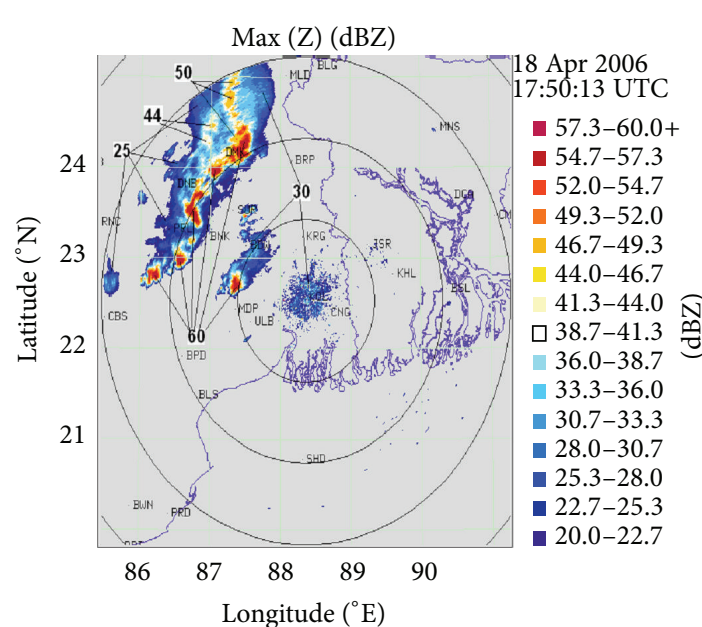

(a)

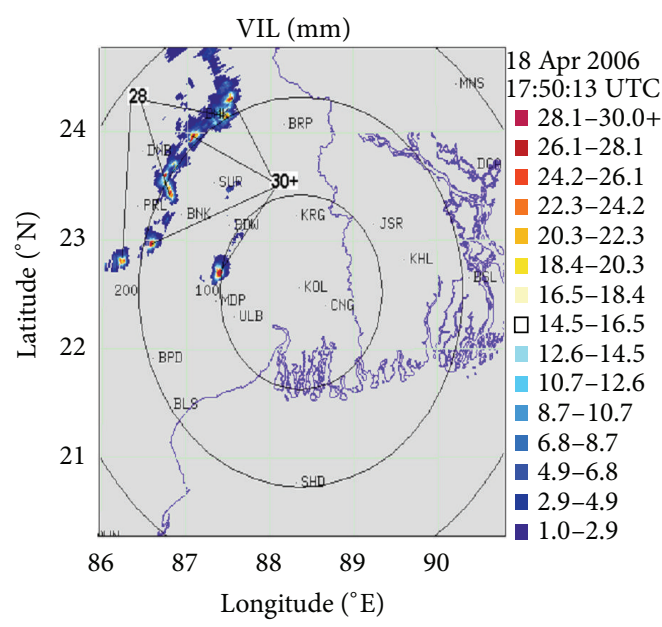

(c)

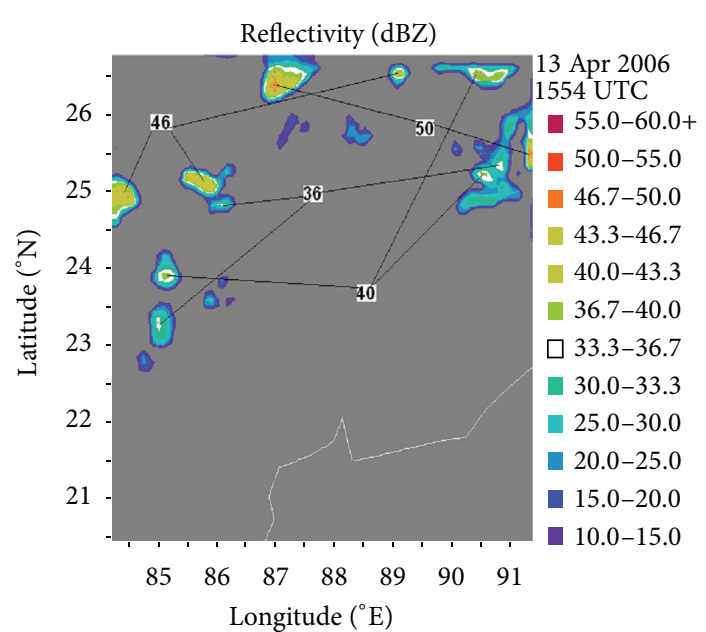

(b)

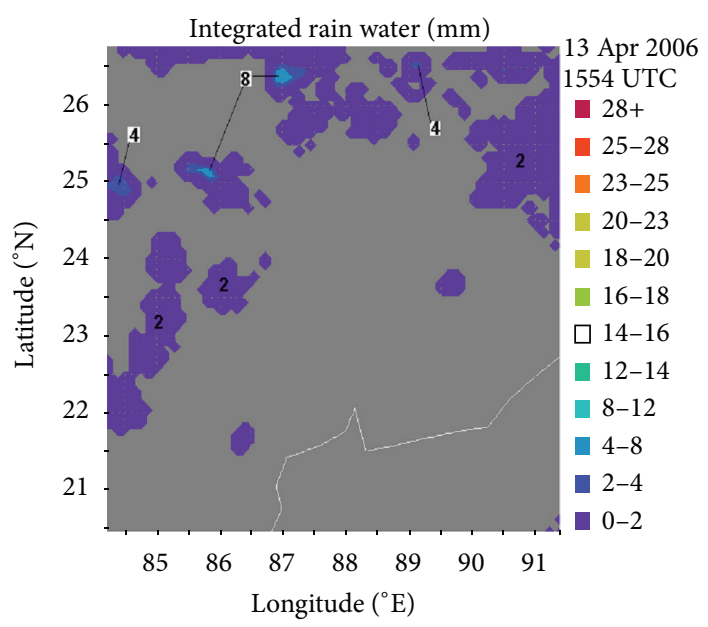

(d)

Figure 18: (a) Radar picture of $\operatorname{Max}(Z)$ at 1850 UTC on April 18, 2006. (b) Model reflectivity at 1648 UTC on April 18, 2006. (c) Radar VIL at 1850 UTC on April 18, 2006. (d) Model IRW at 1648 UTC on April 18, 2006.

from 1150 UTC. The developments here seem to be more haphazard in nature.

The pattern for VIL has consistency with that of $\operatorname{Max}(\mathrm{Z})$ like the previous cases (Figure 17). In this case also the squall line becomes evident from 1650 UTC. A representative figure is given for VIL at 1750 UTC (Figure 18(c)). In case of IRW, the model produces very poor liquid water content throughout the period of comparative study, so that the cut-off value in this case had to be lowered to $4 \mathrm{~mm}$ only. For IRW, a representative figure is given for 1554 UTC (Figure 18(d)) keeping consistency with the corresponding VIL figure. The formations are also haphazard compared to radar observation. In this case, the propagation of the system from initial stage to diminishing stage as seen from radar picture and model simulation is given in Figure 19.

One can conclude that, in case of both reflectivity and cloud liquid water content, there exist similar temporal as well as spatial shifts. This time the model fails to simulate weak cells.
3.5. Comparison with Satellite Observation. To examine MM5 model performance for rain simulation, we are using $3 \mathrm{~B} 42$ (V6) 3 hourly rainfall product of the satellite TRMM, converted to 24-hour accumulated rainfall data as standard. 24 hours extend from 0300 UTC of the concerned date of study to 0300 UTC of the next day. Our domain of study in TRMM extends from $20.00^{\circ} \mathrm{N}-27.00^{\circ} \mathrm{N}$ in latitude and $84.00^{\circ} \mathrm{E}-92.00^{\circ} \mathrm{E}$ in longitude.

At first, let us consider the system of April 10, 2006. From Figure 20(a), one can note that TRMM product of 24-hour accumulated rainfall of $90 \mathrm{~mm}$ and above from 0300 UTC of April 10, 2006, to 0300 UTC of April 11, 2006, is concentrated at the north-east corner of the domain. Otherwise rain is mainly concentrated in the northern part of the domain. Some scattered rain occurs in the central part of the domain.

In case of model simulation (Figure 20(b)) 24-hour accumulated rainfall up to $50 \mathrm{~mm}$ exists over large part of the domain. But heavy rain is concentrated over three patches in east of the central part of the domain. The northern 


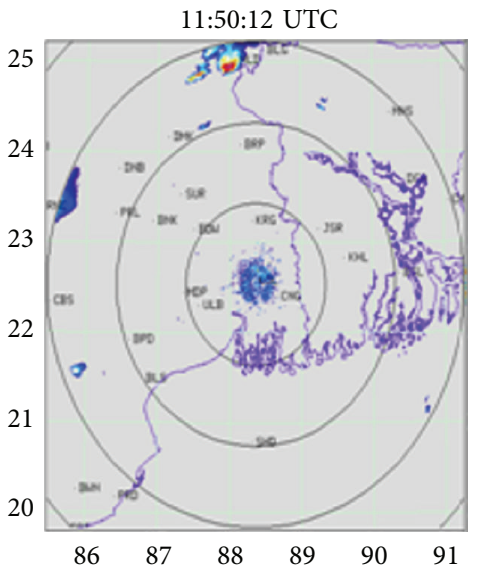

(a)

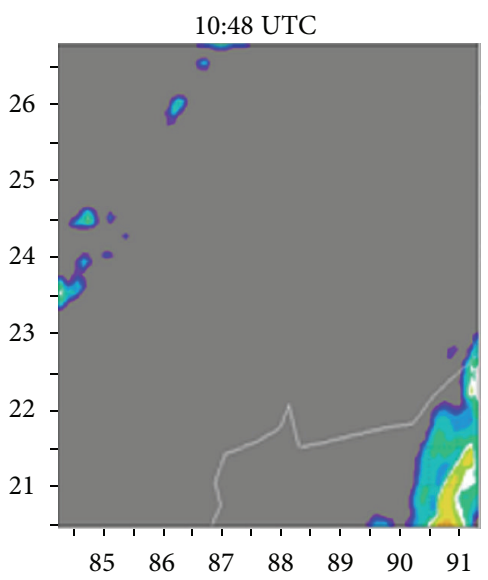

(d)

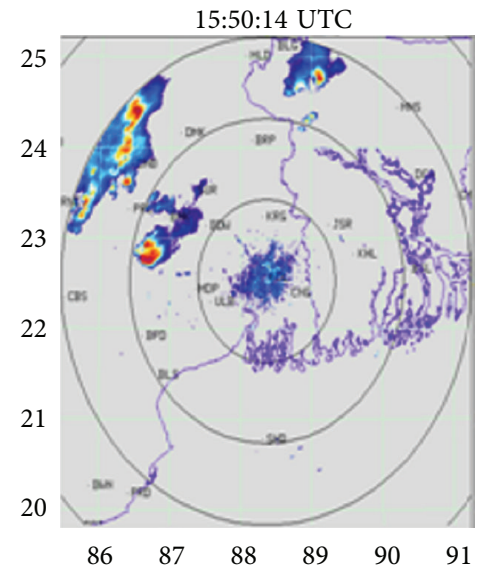

(b)

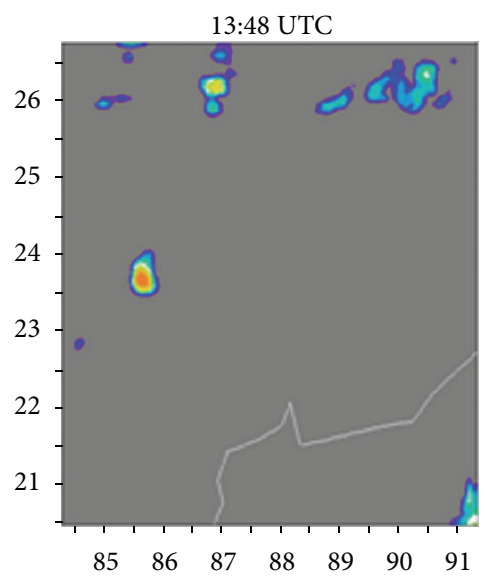

(e)

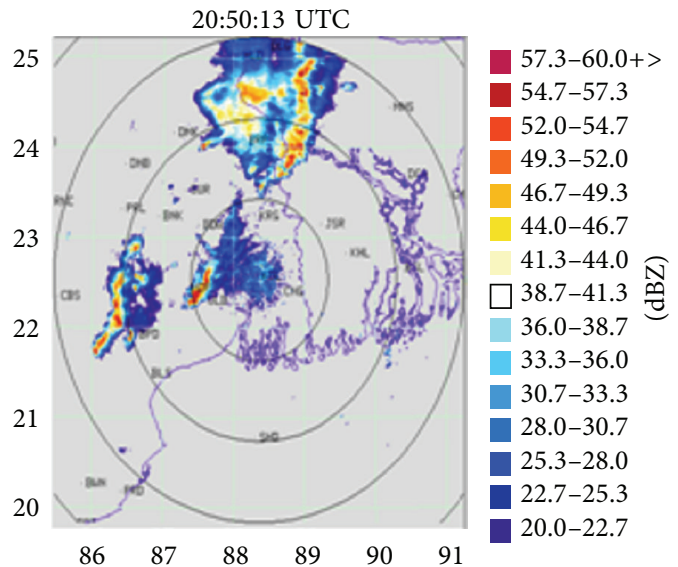

(c)

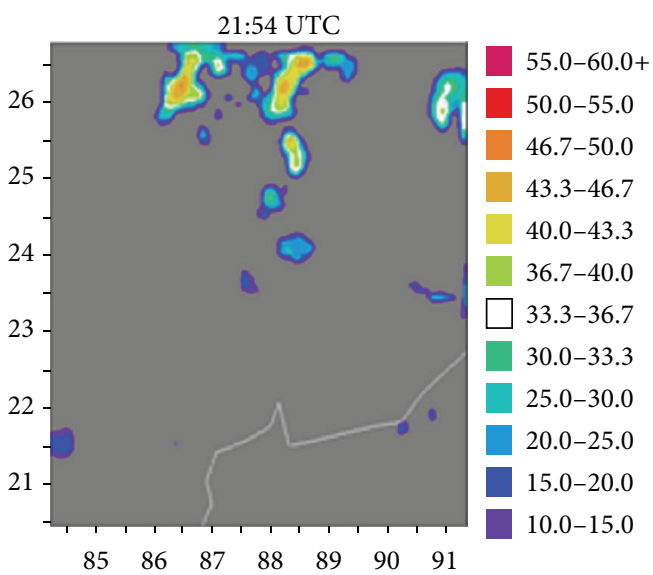

(f)

FIGURE 19: Propagation of the storm on April 18, 2006, as seen from $\operatorname{Max}(Z)$ and model simulated reflectivity pictures.

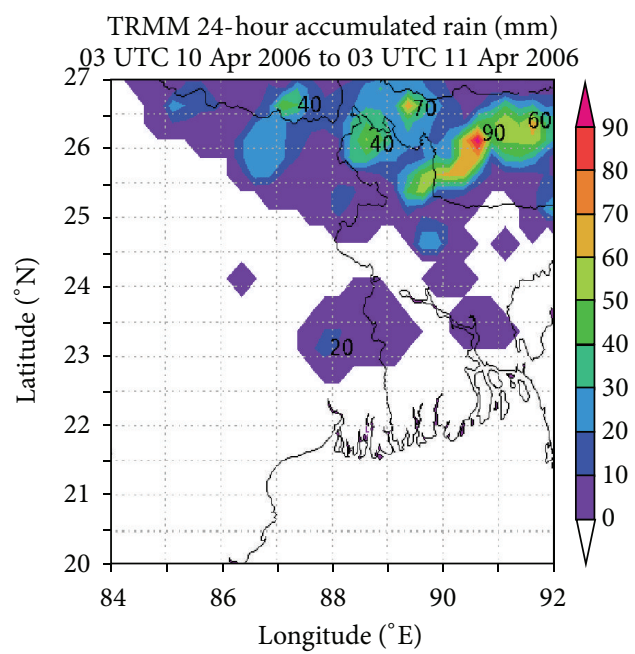

(a)

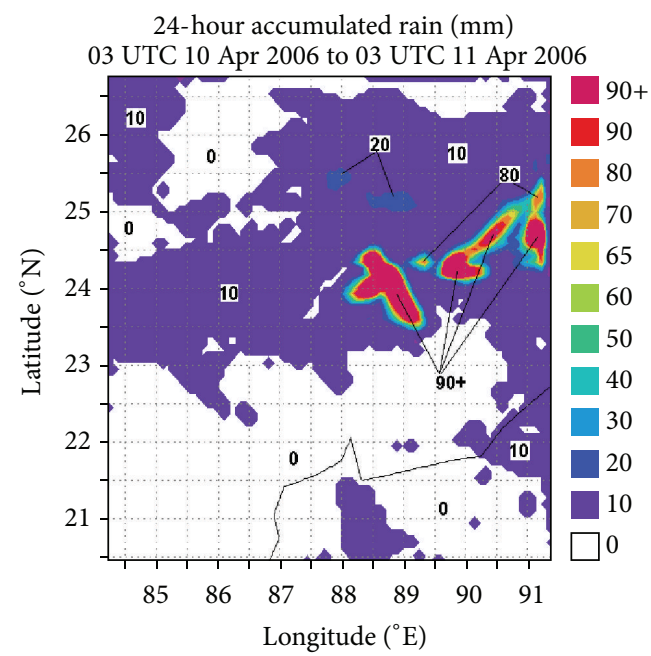

(b)

Figure 20: (a) TRMM produced 24-hour accumulated rainfall from 0300 UTC of April 10, 2006, to 0300 UTC of April 11, 2006. (b) Model produced 24-hour accumulated rainfall from 0300 UTC of April 10, 2006, to 0300 UTC of April 11, 2006. 


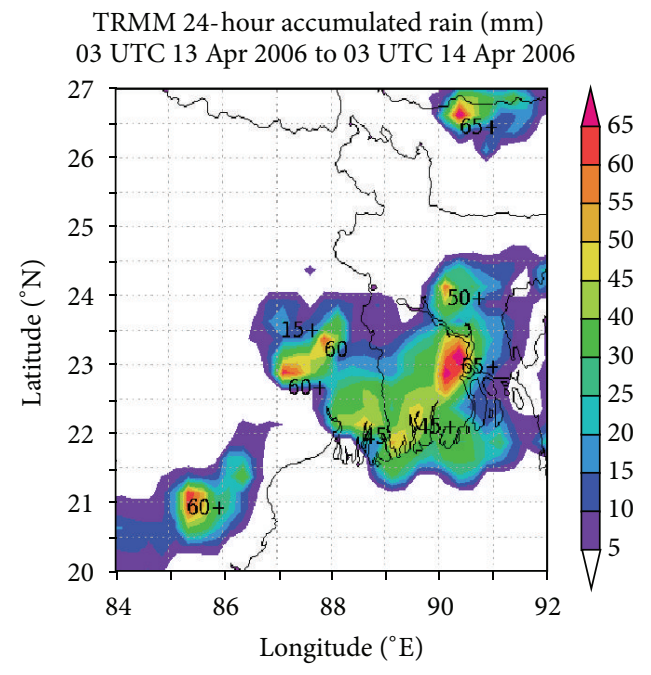

(a)

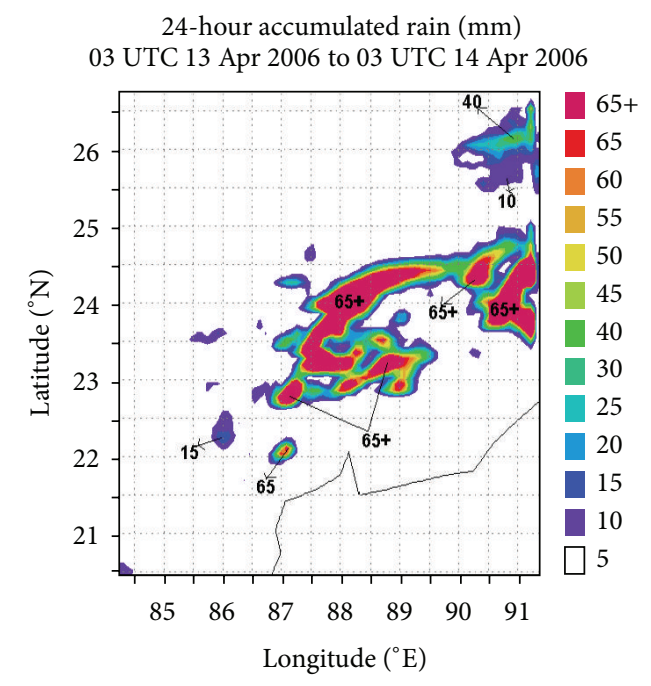

(b)

Figure 21: (a) TRMM produced 24-hour accumulated rainfall from 0300 UTC of April 13, 2006, to 0300 UTC of April 14, 2006. (b) Model produced 24 hour accumulated rainfall from 0300 UTC of April 13, 2006, to 0300 UTC of April 14, 2006.

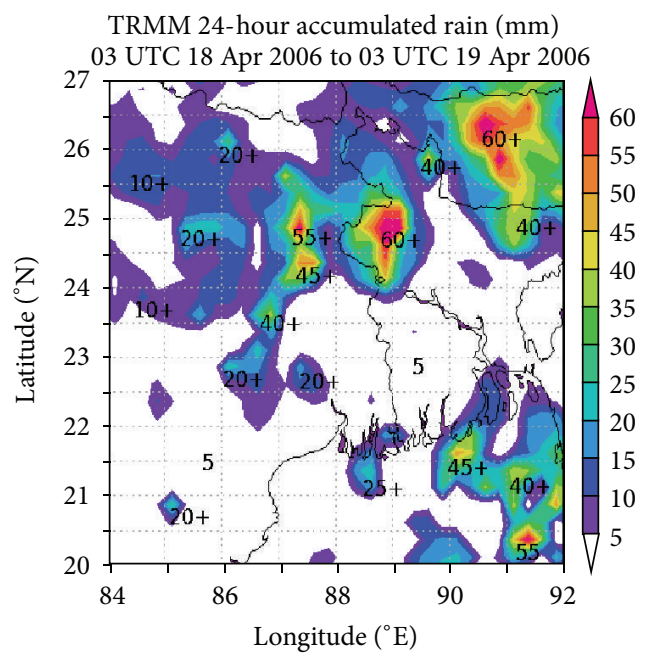

(a)

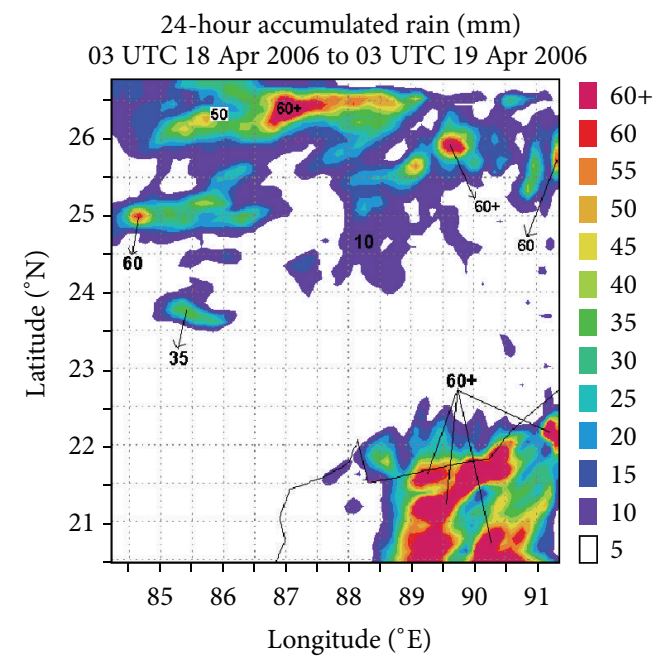

(b)

FiguRE 22: (a) TRMM produced 24-hour accumulated rainfall from 0300 UTC of April 18, 2006, to 0300 UTC of April 19, 2006. (b) Model produced 24-hour accumulated rainfall from 0300 UTC of April 18, 2006, to 0300 UTC of April 19, 2006.

part of the domain is free from any heavy rain. It seems that the heavy rainfall zone of TRMM observation is shifted southward in the model. But the model simulates no rain in the south western part of the domain which indicates a pattern similarity with the IMD observation.

24-hour accumulated rain from 0300 UTC of April 13, 2006, to 0300 UTC of April 14, 2006, obtained as TRMM product is shown in Figure 21(a). The rainfall is concentrated over three zones of the domain. Biggest patch of rainfall occurs over central, east of central, and south central part of the domain. There are two other smaller patches of rainfall at north eastern and south western corner of the domain. Highest rainfall of $65 \mathrm{~mm}$ and above occurs at two places, namely, at east of the central region and north eastern corner of the domain.

24-hour accumulated rainfall as produced by the model over the above mentioned period is shown in Figure 21(b). The rain is concentrated mainly over central and east of the central part of the domain. There is no rain over north eastern and south western corner of the domain as produced by TRMM. So comparing both the pictures one can say about some rainfall pattern similarity. But the rainfall simulated by the model is not so widespread as TRMM produced rain.

At the end let us consider 24-hour accumulated rain from 0300 UTC of April 18, 2006, to 0300 UTC of April 19, 2006. Figure 22(a) represents the rain obtained from satellite 


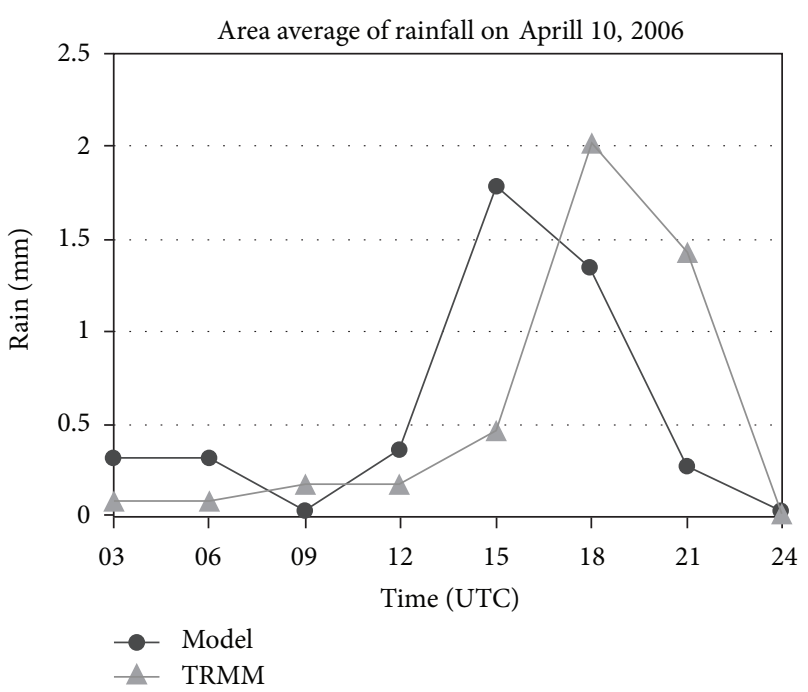

FigURE 23: Area averaged 3-hour accumulated rainfall against time from TRMM satellite data and model output from 0300 UTC to 2400 UTC of April 10, 2006.

observation. Rainfall is dominant over north eastern corner, central part, and south eastern corner of the domain. Apart from that, rain is scattered over different parts of the domain. Maximum rainfall occurs over north eastern corner of the domain and in a patch over north central part of the domain.

Model produced rainfall exists over entire northern part and south eastern corner of the domain (Figure 22(b)). High rainfall occurs over south eastern corner of the domain. Central and south western part of the domain is relatively free from rain. Both the satellite observation and model produce widespread rain, though there exists mismatch location-wise and model produced more rain than observation in south eastern part of the domain. In this case also the above comparison indicates good pattern similarity with the IMD observation.

Next, let us compare the area average rainfall over the concerned domain for every three-hour interval. The amount of rainfall in mm occurring in the previous three hours is plotted against time. It is found that the nature of distribution of 3 hourly accumulated rain is almost identical for satellite observation and model product (Figure 23) for the system of April 10, 2006, except that the peak occurs at 1800 UTC in case of TRMM data and the same occurs at 1500 UTC in case of the model.

In case of the system of April 14, 2006, both the satellite observation and model product (Figure 24) give almost identical distribution of 3 hourly accumulated rainfall. In both the cases the peak rainfall occurs at 1800 UTC.

For the last system occurring on April 18, 2006, the nature of distribution of 3 hourly accumulated rainfall is identical in satellite observation and model product (Figure 25). In both cases, there are two peaks in the distribution occurring at 0600 UTC and 2100 UTC. But, in two cases, the position of higher and lower peak swaps. So from the above comparative study of three days it seems that the model performance of

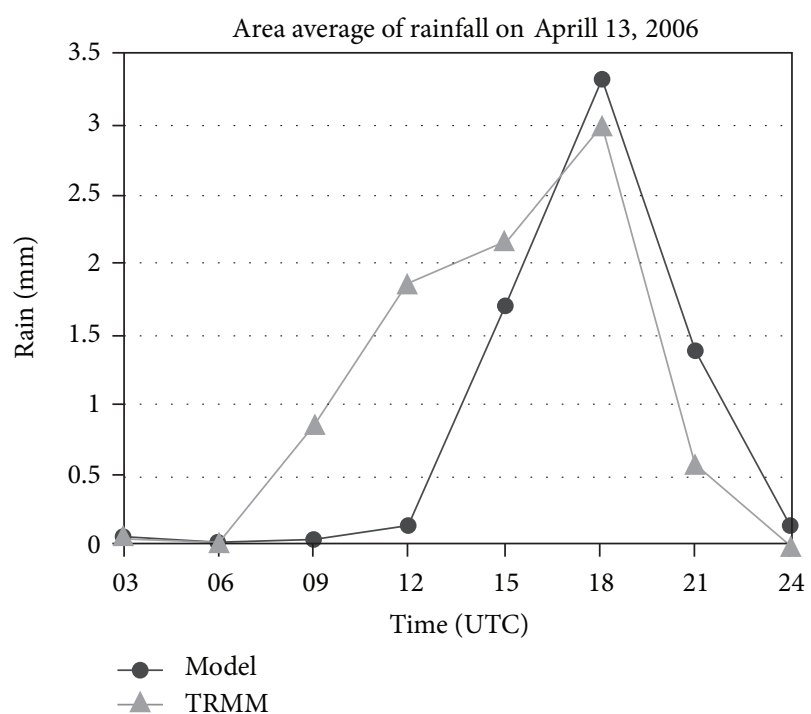

FIGURE 24: Area averaged 3-hour accumulated rainfall against time from TRMM satellite data and model output from 0300 UTC to 2400 UTC of April 13, 2006.

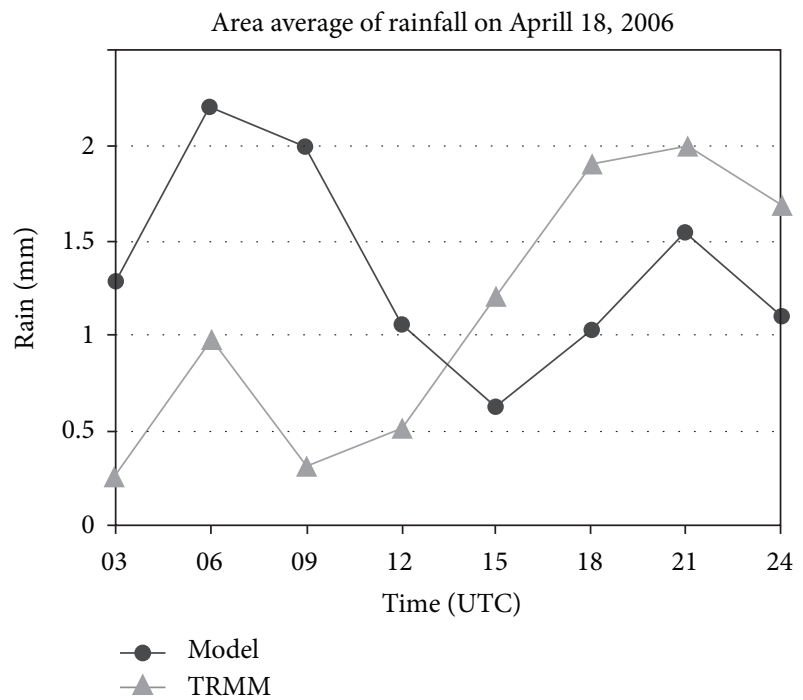

FIGURE 25: Area averaged 3-hour accumulated rainfall against time from TRMM satellite data and model output from 0300 UTC to 2400 UTC of April 18, 2006.

rainfall simulation is better over the whole domain than over a limited region.

\section{Conclusion}

From the above study we have found some strength and some weakness of the model MM5 for simulation of Nor'wester. One can conclude that the model MM5 has the capability to simulate wind squall with all the characteristic features, though there may be some spatial and temporal shift from the actual observation. Overall comparison of the model simulation with Doppler radar and satellite observation is 
good, in spite of spatial and temporal shift. When we come to area average accumulated rainfall at the interval of three hours, the match between satellite observation and model simulation is noteworthy though a three-hour time gap exists between simulation and observation of peak rainfall occurrence in first case. This shows a real redistribution of rain bands in the model simulation in comparison to what is observed. From reflectivity and rainfall comparisons we can say that model better predicts strong convective cells than weak one. Use of more observations from different platforms and use of other techniques like $3 \mathrm{D}$ variation technique for ingestions of observations can remove these weaknesses. Other models with higher resolution can also be utilized in this purpose.

\section{Conflict of Interests}

The authors declare that there is no conflict of interests regarding the publication of this paper.

\section{Acknowledgments}

One of the authors (Prosenjit Chatterjee) thanks University Grand Commission, Government of India, for the sanction of a fellowship to him. Another author (Utpal Kumar De) thanks the All India Council for Technical Education, Government of India, for the sanction of Emeritus Fellowship and the present work is associated with fellowship. All the authors thank India Meteorological Department for providing the necessary Doppler radar data. Thanks are also due to Dr. S. K. Ghosh, the retired DDGM, Indian Meteorological Department, for going through the paper and making valuable suggestions.

\section{References}

[1] India Meteorological Department, "Nor'wester of Bengal," IMD Technical, 1944.

[2] P. K. Patra, M. S. Santhanam, K. V. J. Potty, M. Tewari, and P. L. S. Rao, "Simulation of tropical cyclones using regional weather prediction models," Current Science, vol. 79, no. 1, pp. 70-78, 2000.

[3] D. V. B. Rao and D. H. Prasad, "Sensitivity of tropical cyclone intensification to boundary layer and convective processes," Natural Hazards, vol. 41, no. 3, pp. 429-445, 2007.

[4] C. V. Srinivas, R. Venkatesan, D. V. Bhaskar Rao, and D. Hari Prasad, "Numerical simulation of Andhra severe cyclone: model sensitivity to the boundary layer and convection parameterization," Pure and Applied Geophysics, vol. 164, no. 8-9, pp. 1465-1487, 2007.

[5] S. Sandeep, A. Chandrasekar, and S. K. Dash, "On the prediction of tropical cyclones over the Indian region using a synthetic vortex scheme in a mesoscale model," Pure and Applied Geophysics, vol. 164, no. 8-9, pp. 1443-1463, 2007.

[6] C. U. Mohanty and M. Mandal, "Simulation of track and intensity of the Bay of Bengal cyclones using NCAR meso-scale model," in WRF/MM5 Users' Workshop, Boulder, Colo, USA, 2005.
[7] V. Kumar and A. Chandrasekar, "Ensemble lagged forecasts of a monsoon depression over India using a meso-scale model," Atmosfera, vol. 20, no. 1, pp. 25-44, 2007.

[8] P. Zuideme, "Convective clouds over the Bay of Bengal," Monthly Weather Review, vol. 131, pp. 780-789, 2003.

[9] S. Das, A. K. Das, U. C. Mohanty, and R. K. Paliwal, "Mountain weather forecasts over the Indian region using MM5 model," in Proceedings of the National Snow Science MEET-01, pp. 65-68, November 2001.

[10] U. C. Mohanty, M. Mandal, and S. Raman, "Simulation of Orissa super cyclone (1999) using PSU/NCAR mesoscale model," Natural Hazards, vol. 31, no. 2, pp. 373-390, 2004.

[11] A. J. Litta and U. C. Mohanty, "Simulation of a severe thunderstorm event during the field experiment of STORM programme 2006, using WRF-NMM model," Current Science, vol. 95, no. 2, pp. 204-214, 2008.

[12] A. J. Litta, U. C. Mohanty, and S. C. Bhan, "Numerical simulation of a tornado over Ludhiana (India) using WRF-NMM model," Meteorological Applications, vol. 17, no. 1, pp. 64-75, 2010.

[13] M. Mandal and U. C. Mohanty, "Simulation of severe landfalling bay of bengal cyclones during 1995-1999 using mesoscale model MM5," Marine Geodesy, vol. 33, no. 4, pp. 315-337, 2010.

[14] A. J. Litta, S. M. Ididcula, U. C. Mohanty, and S. K. Prasad, "Comparison of thunderstorm simulations from WRF-NMM and WRF-ARW models over east indian region," The Scientific World Journal, vol. 2012, Article ID 951870, 20 pages, 2012.

[15] A. J. Litta, U. C. Mohanty, S. Das, and S. Mary Idicula, "Numerical simulation of severe local storms over east India using WRF-NMM mesoscale model," Atmospheric Research, vol. 116, pp. 161-184, 2012.

[16] A. J. Litta, U. C. Mohanty, and S. M. Idicula, "The diagnosis of severe thunderstorms with high-resolution WRF model," Journal of Earth System Science, vol. 121, no. 2, pp. 297-316, 2012.

[17] O. P. Madan, N. Ravi, and U. C. Mohanty, "Forecasting peak surface gust wind in association with thunderstorm activity during pre-monsoon season at Delhi," MAUSAM, vol. 52, no. 2, pp. 385-396, 2001.

[18] P. Chatterjee, D. Pradhan, and U. K. De, "Simulation of local severe storm by mesoscale model MM5," Indian Journal of Radio and Space Physics, vol. 37, no. 6, pp. 419-433, 2008.

[19] K. A. Browning, "Quantitative precipitation forecasting," Weather, vol. 58, no. 3, pp. 126-127, 2003.

[20] D. J. Gagne II, A. McGovern, and M. Xue, "Machine learning enhancement of storm-scale ensemble probabilistic quantitative precipitation forecasts," Weather and Forecasting, vol. 29, pp. 1024-1043, 2014.

[21] G. A. Grell, J. Dudhia, and D. R. Stauffer, "A description of 5th generation Penn State/NCAR Meso-scale Model (MM5)," NCAR Technical Note NCAR/TN-398+STR, NCAR, 1994.

[22] P. Schultz, "An explicit cloud physics parameterization for operational numerical weather prediction," Monthly Weather Review, vol. 123, no. 11, pp. 3331-3343, 1995.

[23] G. A. Grell, "Prognostic evaluation of assumptions used by cumulus parameterizations," Monthly Weather Review, vol. 121, no. 3, pp. 764-787, 1993.

[24] J. Dudhia, "A multi-layer soil temperature model for MM5," in Proceedings of the 6th Annual MM5 Users' Workshop, Boulder, Colo, USA, 1996.

[25] A. Arakawa and W. H. Schubert, "Interaction of a cumulus cloud ensemble with the large scale environment. Part I," Journal of the Atmospheric Sciences, vol. 31, pp. 674-701, 1974. 
[26] G. Cressman, "An operational objective analysis system," Monthly Weather Review, vol. 87, no. 10, pp. 367-374, 1959.

[27] W. A. Nuss and D. W. Titley, "Use of multiquadric interpolation for meteorological objective analysis," Monthly Weather Review, vol. 122, no. 7, pp. 1611-1631, 1994.

[28] WMO, "Tropical cyclone operational plan for the Bay of Bengal and the Arabian sea," Technical Document No. 84, WMO, Geneva, Switzerland, 2008.

[29] Air Force Administrative College, Training Notes Meteorology, Air Force Administrative College, Coimbatore, India, 1968.

[30] M. J. Colmer, On the Character of Thunderstorm Gust Fronts, Royal Aircraft Establishment, Bedford, UK, 1976.

[31] R. C. Goff, "Vertical structure of thunderstorm outflows," Monthly Weather Review, vol. 104, no. 11, pp. 1429-1440, 1976. 

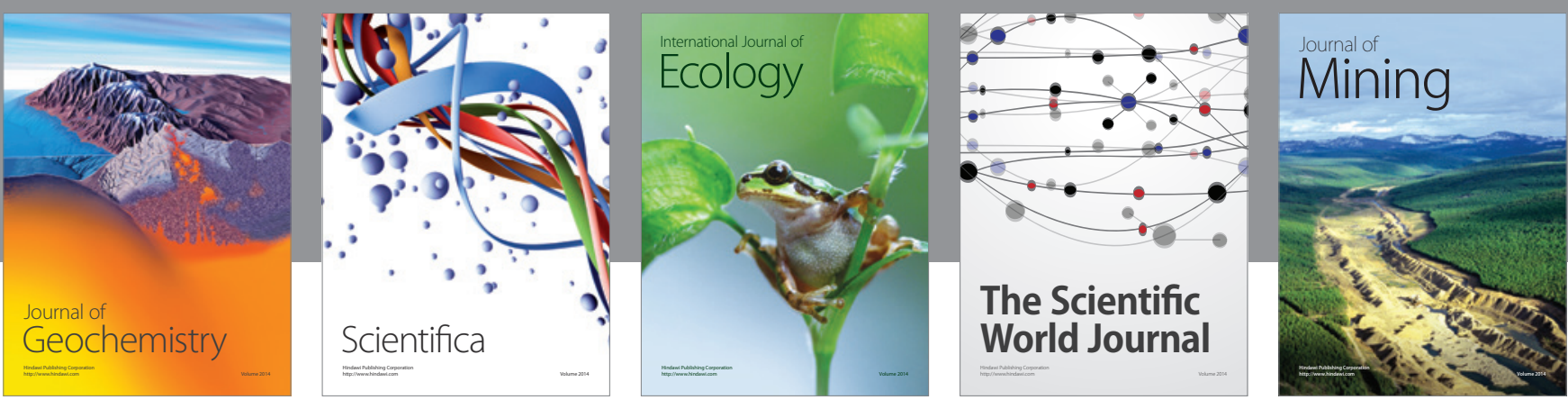

The Scientific World Journal
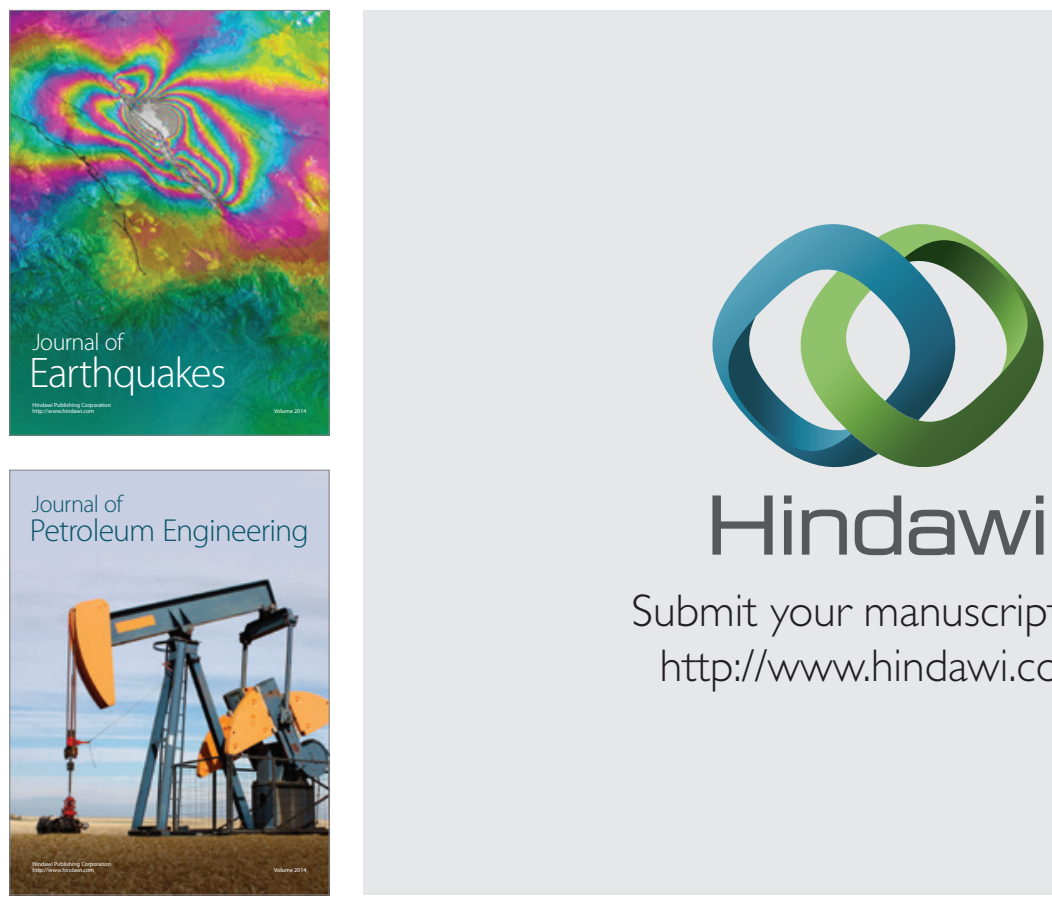

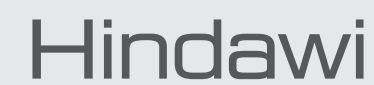

Submit your manuscripts at

http://www.hindawi.com
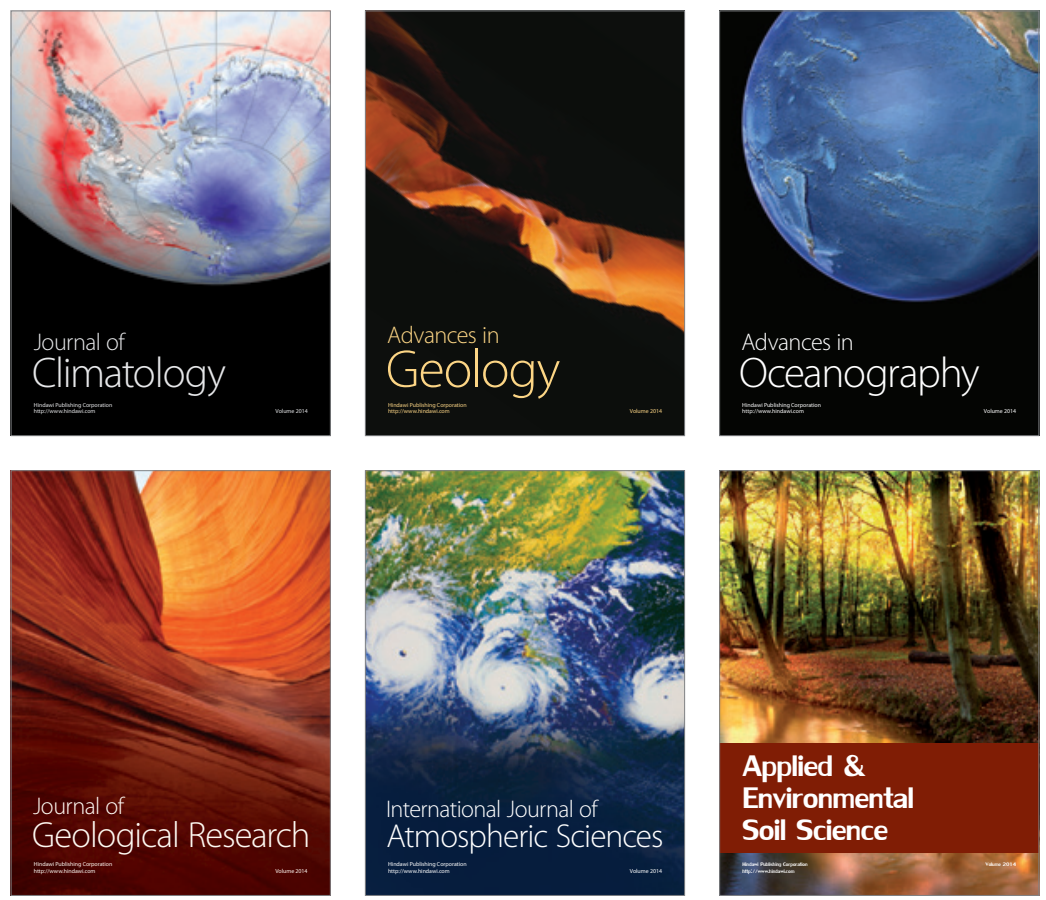
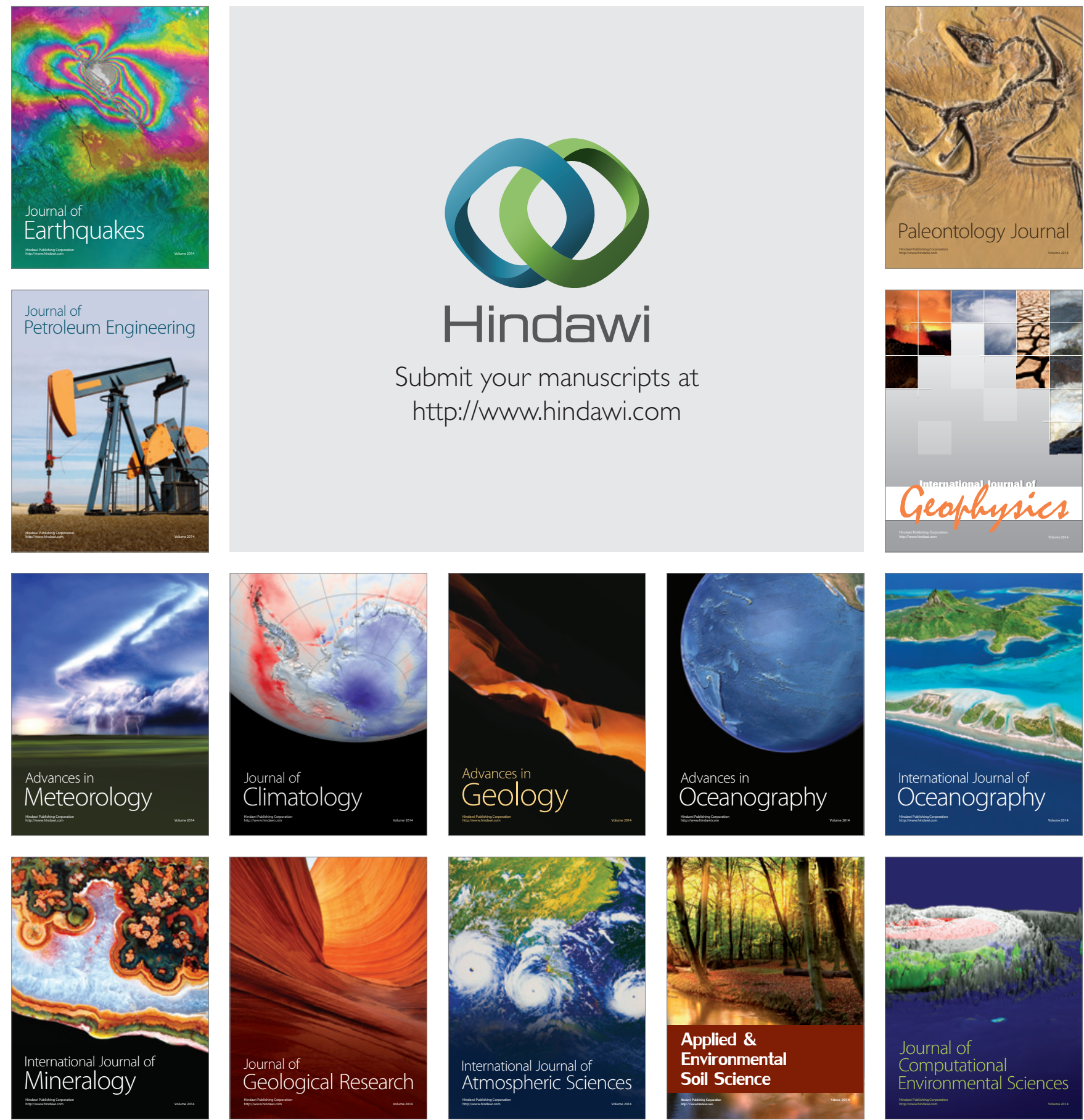